\title{
Regional precipitation-frequency analysis and spatial mapping for 24-hour and 2-hour durations for Washington State
}

\author{
J.R.Wallis ${ }^{1}$, M.G. Schaefer ${ }^{2}$, B.L. Barker ${ }^{2}$ and G.H. Taylor ${ }^{3}$ \\ ${ }^{1}$ Yale University, Chemical Engineering Department, Environmental Engineering Program, 9 Hillhouse Avenue, New Haven, CT 06520-8286, USA \\ ${ }^{2}$ MGS Engineering Consultants, Inc., 7326 Boston Harbor Road NE, Olympia, WA 98506, USA \\ ${ }^{3}$ Oregon Climate Service, Oregon State University, Strand Hall Room 326, Corvallis, Oregon, 97331-2209, USA
}

Email for corresponding author: James.Wallis@Yale.edu

This preamble explains why a paper on precipitation probabilities at the 2-hour and 24-hour time periods for the State of Washington, USA, was solicited for a special symposium honouring Dr. McCulloch's contributions to hydrology. Indeed, the specific subject of the paper has no particular connection with Dr. McCulloch's technical specialties or the thrust of IH work, but it does have much to do with Dr Mc Culloch's prowess and vision for running a research institute.

In 1984, I was invited to spend a Sabbatical year at IH to work on the then new technique of Regional Probability Weighted Moments (PWM) in connection with Generalised Extreme Value (GEV) distribution. The IH Flood Studies Report (FSR) had used the GEV distribution with a graphical method involving rather arbitrary and subjective steps in its fitting procedure for determining the regional distributions to use in different parts of the UK. Because physically impossibly-large flood probabilities had been produced by the FSR in connection with some Scottish dams, there was a controversy with large economic and social implications. I, working together with Jon Hosking, a young, very bright mathematical statistician employed by IH, addressed the problem and devised a PWM solution for the GEV so that the FSR flood probability estimation difficulty was resolved which was invaluable to IH at the time

After much more research in the UK and the USA, a book Regional Frequency Analysis; An Approach Based on L-Moments by J.R.M. Hosking and J.R. Wallis was published by Cambridge University Press. It is worth noting that the Regional L-moment algorithm is numerically equivalent to the Regional PWM algorithm, but the Regional L-moment approach is much more complete and powerful; and has appeared in a myriad of other investigations published in hydrological and meteorological journals worldwide, as well as in other studies reported at this General Assembly. Presumably Regional L-moments would have been discovered eventually, but their prompt appearance can be largely attributed to Dr. McCulloch's stewardship of IH, and in particular on his insistence on the value of inviting outside scientists to IH.

\begin{abstract}
This study is an update of the information contained in the precipitation-frequency atlas published by the US National Weather Service in 1973. Data collection for the NWS study ended in 1966 while this study uses the current data base which more than doubles the record length used in the NWS study. Washington State has highly variable topography and climate; in particular Mean Annual Precipitation (MAP) varies from over 260 inches a year to less than 7 inches. Steep high mountain ranges provide very wet slopes as well as pronounced rain shadows with large climate changes occurring in relatively short distances. In addition there are four distinct sources for the atmospheric moisture needed for precipitation which gives rise to complex seasonal and spatial interactions. The PRISM mapping system used in this study has greatly improved the spatial mapping of precipitation and increased the reliability of estimates of precipitation in the broad areas between precipitation measurement stations. Further, the development and use of regional L-Moments has greatly improved the reliability of precipitation magnitude-frequency estimates, particularly for the rarer and more extreme storms. Washington State could be specified adequately by 12 regions for the purposes of estimating the 2-hour and 24 hour precipitation frequencies. Within each region algorithms were developed for L$\mathrm{CV}$ and L-Skewness expressed as functions of the MAP. The GEV distribution was acceptable statistically for all regions up to the 1 in 500 recurrence interval, beyond which the four-parameter Kappa distribution is recommended. The estimated changes in precipitation magnitudes for a given frequency as regional boundaries were crossed were found to be small, and well within the expected differences likely from sampling errors. An interesting transition zone was observed at the eastern edge of the Cascade foothills, associated with the maxima having a seasonal change from autumn-winter synoptic scale general storms in the west to spring-summer maxima in the east that were produced by a mix of storm types. (Comment: storms were a mix of general storms and more-isolated convective storms).
\end{abstract}

Keywords: Extreme precipitation events, precipitation probablities, Generalised Extreme Value distribution, Regional Probablity Weighted Moments 


\section{Overview}

This paper documents the findings of regional precipitationfrequency analyses of 24-hour and 2-hour precipitation annual maxima for Washington State. It also describes the procedures used for spatial mapping of the precipitationfrequency estimates for selected recurrence intervals. The study was done in two parts. First, western Washington, comprising the area west of the Cascade Mountain crest, was completed in March 2002 (Schaefer et al., 2002) and second, eastern Washington, comprising the remainder of the state, was completed in January 2006 (Schaefer et al., 2006). The report can be considered as an update of the 1973 precipitation-frequency atlas published by the National Weather Service (NOAA Atlas 2 ) (Miller et al., 1973). Data collection for the NWS study ended in 1966, while this study includes the 37-years of record collected since 1966, as well as additional data sources not available in 1966. These additional data provide a precipitation database that more than doubles the record length available in the original NWS study.

Since the original 1966 study, major advances have been made in the methods for statistical analysis of precipitation annual maxima, and for spatial mapping of precipitation in complex terrain. Specifically, L-Moment statistical analysis techniques (Hosking, 1990; Hosking and Wallis, 1997) conducted within a regional framework have greatly improved the reliability of precipitation magnitudefrequency estimates, particularly for rare storm events. Development of the GIS based PRISM model (Daly et al., 2002) incorporating digital terrain data and its interaction with the climatic storm patterns has also improved the spatial mapping of precipitation and increased the reliability of estimating precipitation in the broad areas between precipitation measurement stations. These methodologies are particularly effective in areas with the high topographic and climatic variability that exists in Washington State. Both of these methodologies have been utilised in conducting the precipitation-frequency analyses and in developing the isopluvial maps for selected recurrence intervals.

As the study for eastern Washington was nearing completion, the Oregon Climate Service released a high resolution update of the PRISM map of mean annual precipitation (MAP), for Washington State (Spatial Climate Analysis Service, 2005). The new map of MAP was produced using data from 1971-2000 and incorporated 10 additional years of SNOTEL data in mountain areas, an improved moisture trajectory inflow model, and an improved digital terrain model with 30 -arc-seconds resolution, resulting in higher resolution precipitation mapping. The improvements resulted in some important changes to previously mapped values of MAP in some mountain and foothill areas.

Colour-shaded isopluvial maps depicted in this paper reflect the findings of both the above component studies using updated data and utilising the 1971-2000 base map of MAP (Spatial Climate Analysis Service, 2005).

\section{Study area}

While Washington is the area of interest, the study area was expanded to provide additional data in border areas. The study area included portions of southern British Columbia (Oregon Climate Service, 2000), north-eastern Oregon and western Idaho (Oregon Climate Service, 2005) (Fig. 1). Specifically, the Washington study area is bounded on the north at latitude $49^{\circ} 30^{\prime} \mathrm{N}$, bounded to the south by latitude $45^{\circ} 00^{\prime} \mathrm{N}$, and bounded to the east at latitude $116^{\circ} 00^{\prime} \mathrm{W}$. Addition of the out of State precipitation stations provided data from areas climatologically similar to data-sparse areas in Washington itself, such as locations in the Cascade Mountains, Blue Mountains and Selkirk Mountains.

\section{Climatic and meteorological characteristics of the study area}

ANNUAL PRECIPITATION

Figure 1 shows that the mean annual precipitation within the Washington study area varies dramatically from the western slopes of the Olympic Mountains, ( $>250$ inches, $6.35 \mathrm{~m}$ ), to the desert areas of the Columbia plateau in central Washington, ( $<10$ inches, $0.25 \mathrm{~m})$.

\section{WEATHER SYSTEMS AND SOURCES OF ATMOSPHERIC MOISTURE}

The two ingredients needed for precipitation to occur are a source of atmospheric moisture and a meteorological mechanism to release that moisture. There is also a greater potential for extreme precipitation events when the source of moisture originates in areas with warmer temperatures and higher dewpoints. There are four generalised geographic areas that are sources of atmospheric moisture to the study area (Miller et al., 1973; NWS, 1966, 1994) and each has differing characteristic temperatures and dewpoints. The source areas are:

(1) the Gulf of Alaska;

(2) the Pacific Ocean north of the Canadian border,

(3) the Pacific Ocean from as far south as latitude $20^{\circ} \mathrm{N}$ near the Hawaiian Islands, and 


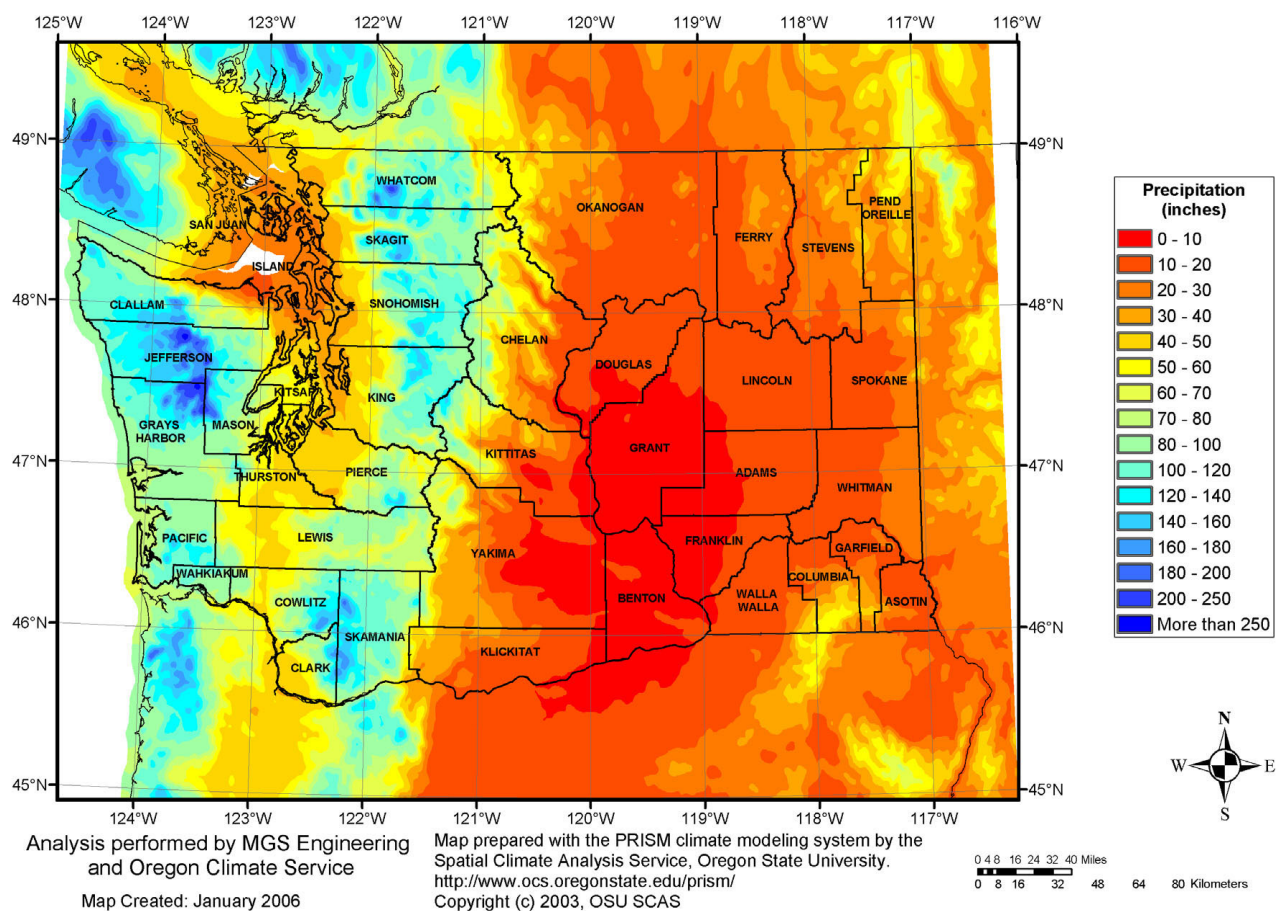

Fig. 1. Mean Annual Precipitation for Washington State Study Area

(4) the Gulf of Mexico that occasionally has storms that penetrate sufficiently north to be a source for precipitation in eastern Washington during the warmer months.

Storm systems (Miller et al., 1973; NWS, 1966, 1994) moving in a south-easterly direction out of the Gulf of Alaska primarily affect northern portions of the study area and generally contain cooler temperatures and dewpoints. Storm systems originating over the Pacific Ocean are the most common while those that originate from southerly latitudes near the Hawaiian Islands have been responsible for many of the largest long-duration precipitation events experienced in the winter months. Synoptic-scale cyclonic weather systems and associated fronts generally provide the mechanism for producing precipitation annual maxima at the 24-hour and longer durations. Precipitation is enhanced in mountain areas as atmospheric moisture is lifted over the Olympic, Cascade, Selkirk, and Blue Mountains. This orographic component of precipitation has the greatest effect at 24-hour and longer time scales, and can enhance the total accumulation of precipitation significantly over several days. Precipitation annual maxima at the 24-hour duration occur predominately in the autumn and winter seasons throughout western Washington as well as on the eastern slopes of the Cascade Mountains. The remainder of eastern Washington experiences precipitation annual maxima at the 24-hour duration in both the autumn and winter months as well as in spring and summer.

Precipitation annual maxima at the 2-hour duration may occur as a result of several different storm mechanisms. They may occur due to low-to-moderate convective activity associated with a large-scale synoptic weather system. In this case, the 2-hour annual maxima are embedded within much longer duration storm events. They may also occur due to more intense convective activity that may, or may not, be associated with an organised weather system. In this latter case, the 2-hour annual maxima are often associated with 'thunderstorms' in the spring and summer, which are short-duration localised storm events with limited areal coverage. The moisture source for thunderstorm events may originate over the Pacific Ocean or, in some cases, as far south as the Gulf of Mexico (NWS, 1994) ${ }^{1}$.

\section{Data sources}

A precipitation annual maximum is the greatest precipitation amount in a 12-month period for a specified duration at a given measurement site. The water-year, October 1st to September 30th was used for determining precipitation annual maxima for the 24-hour and 2-hour durations in this study.

Precipitation annual maxima and associated storm dates were obtained from precipitation records from a variety of 
sources. Most of the data were obtained from the electronic files of the National Climatic Data Center (NCDC). Data for southern British Columbia were obtained from the Canadian Atmospheric Environment Services Agency

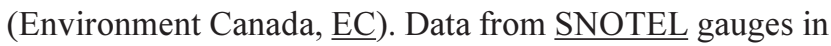
mountains areas were obtained from the electronic files of the Natural Resources Conservation Service (NRCS).

\section{PRECIPITATION GAUGE TYPES, METHODS OF MEASUREMENT AND REPORTING}

Precipitation is measured by a variety of devices and reported by a number of different agencies in the United States and Canada. Descriptions of the gauge types and reporting methods are summarised below.

Daily Gauges: Daily gauges in US and Canada are standardised devices comprising simple vertical cylinders open to the atmosphere. A variety of shields for protection from the wind are used in both countries, with shields being more common now than in the past. Precipitation is measured once each day at a specified time and represents the precipitation for the previous 24-hours.

Automated Gauges: Automated gauges such as weighing buckets, Fisher-Porter tipping buckets, and other types of tipping buckets can provide information about precipitation intensity on various time scales. The standards in both the US and Canada are for reporting either hourly or at 15-min. intervals. Weighing bucket gauges with paper strip charts came on-line around 1940-1945 in the US and many were installed in Canada in the 1950s and 1960s. Tipping bucket gauges and automated reporting systems were installed at many sites beginning in the 1970s. These gauges are often given the generic term hourly gauges to distinguish them from daily gauges.

SNOTEL Gauges: SNOTEL gauges are a type of automated gauge commonly used in mountain areas. They have external heating systems and are designed for cold weather operation. Precipitation that falls as snow is converted to liquid water for measurement. SNOTEL gauges typically report precipitation on a daily basis on a midnight-to-midnight reporting schedule.

\section{NUMBER OF GAUGES AND GAUGE TYPES}

The number of gauges and gauge types used in the regional analyses are summarised in Tables $1 \mathrm{a}, \mathrm{b}$. At many precipitation measurement sites in the US and BC, both daily and hourly precipitation gauges are co-located and this occurred at 129 stations in Washington, Oregon, Idaho and British Columbia. To avoid duplication, the record from the gauge with the longest record was used in the analyses for the 24-hour duration. When both the daily and hourly records were of similar length, the record from the hourly gauge was selected. The precipitation station networks are shown in Figs. 2a,b for the 24-hour and 2-hour durations, respectively

\section{Data screening and quality checking}

Extensive efforts in screening and quality checking the annual maxima data were necessary to eliminate false annual maxima associated with a variety of data measurement, reporting and transcription errors, and incomplete reporting during some years. The record for all sites and climaticyears was checked for completeness. In addition, all records were scanned for anomalously small or large precipitation amounts, and the Hosking and Wallis (1997, 1993) measure of discordancy was also used to identify gauges the sample statistics of which were markedly different from the majority of gauges in a given region. Suspicious gauges and data were checked to verify the validity of records. Nearby sites were also checked to corroborate the magnitude and date of

Table 1a. Number and type of gauges utilised for analyses of 24hour annual maxima

\begin{tabular}{llll}
\hline Station location & $\begin{array}{l}\text { Daily } \\
\text { gauge }\end{array}$ & $\begin{array}{l}\text { Hourly } \\
\text { gauge }\end{array}$ & $\begin{array}{l}\text { SNOTEL } \\
\text { gauge }\end{array}$ \\
\hline British Columbia & 91 & 6 & 0 \\
Washington & 200 & 78 & 34 \\
Idaho & 20 & 9 & 10 \\
Oregon & 62 & 38 & 22 \\
TOTAL & $\mathbf{3 7 3}$ & $\mathbf{1 3 1}$ & $\mathbf{6 6}$
\end{tabular}

$129 \mathrm{NCDC}$ and $\mathrm{BC}$ stations have co-located daily and hourly gauges (not included above)

Table $1 b$. Number and type of gauges utilised for analyses of 2hour annual maxima

\begin{tabular}{lc}
\hline Station location & Hourly gauge \\
\hline British Columbia & 26 \\
Washington & 110 \\
Idaho & 14 \\
Oregon & 44 \\
TOTAL & $\mathbf{1 9 4}$ \\
\hline
\end{tabular}




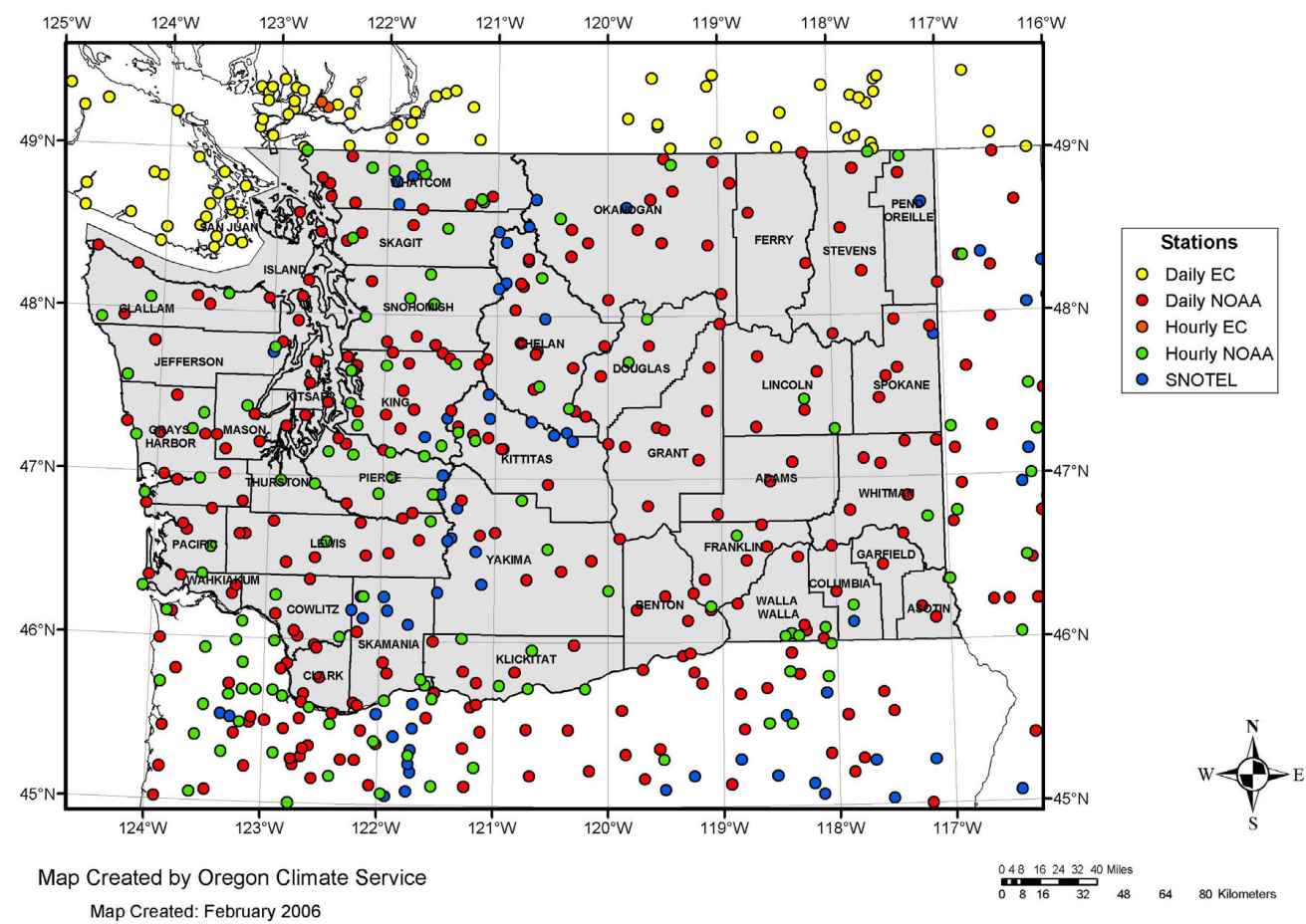

Fig. 2a. Precipitation gauging network for analysis of 24-hour precipitation

Climate Stations for 2-hour Analysis

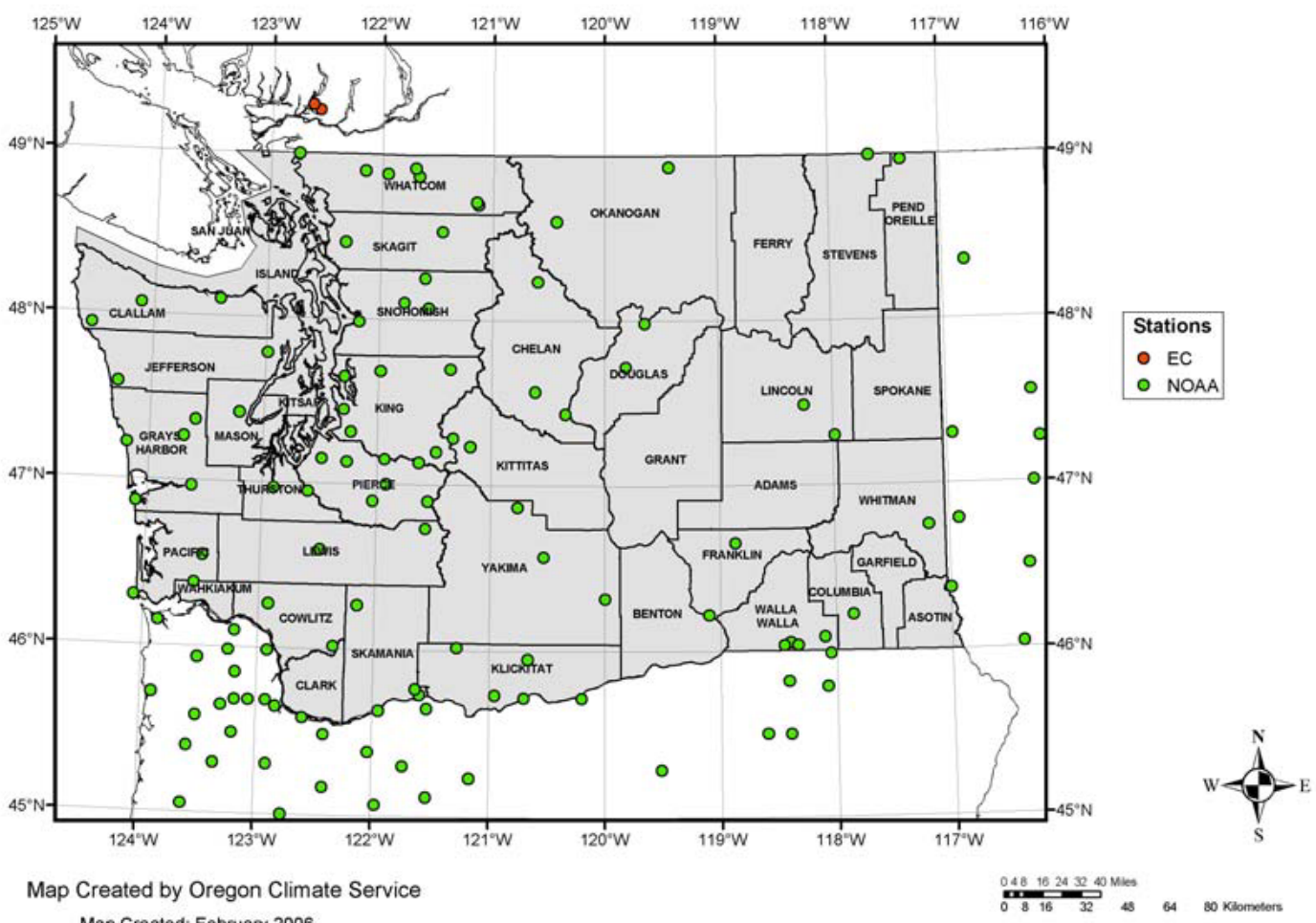

Fig.2b. Precipitation gauging network for analysis of 2-hour precipitation 
occurrence of any anomalously small or large precipitation annual maximum. Data that were clearly erroneous were removed from the datasets. (Note: the NCDC database is known to include many spurious values; for instance, in one study, $38 \%$ of the NCDC sites were found to have one or more obviously spurious values included amongst the values reported — see Wallis et al. (1991).

\section{STATIONARITY AND SERIAL INDEPENDENCE}

Two underlying assumptions inherent in frequency analyses are the stationarity of the data over the period of observation and use, and the serial independence of the data at a given site (gauge). As part of the data screening process, standard statistical tests for stationarity and serial independence were conducted. Inter-station correlation analyses were also conducted to assess the relative amount of correlation between annual maxima at nearby gauges.

The stationarity criterion, that the data must be free from trends during the period of observation, was confirmed for each duration, by standard linear regression techniques where the station data were first rescaled by division by the at-site mean and then regressed against the year of occurrence minus 1900. This approach allowed comparisons to be made among all gauges and to interpret the relative magnitude of any trend over the past century. The average values of the slope parameter were $+0.05 \%$, and $+0.11 \%$ for the 24-hour, and 2-hour durations, respectively. The regression results for the collective group of gauges were tested against a null hypothesis of zero slope (stationarity). The null hypothesis could not be rejected at the $5 \%$ level, so the data at both durations were accepted as stationary.

To confirm the independence of the annual maxima data, serial correlation coefficients were computed for the data at each gauge for the annual, 24-hour and 2-hour durations. The regression results for the collective group of gauges were tested against a null hypothesis of zero serial correlation (independence). The null hypothesis could not be rejected at the $5 \%$ level so, as expected, the annual maxima data were found to be serially independent.

\section{Regional frequency analysis methodology}

The cornerstone of a regional frequency analysis is that data from sites within a homogeneous region can be pooled to improve the reliability of the magnitude-frequency estimates for all sites. A homogeneous region may be a geographic area delineated on a map or it may be a collection of sites having similar characteristics pertinent to the phenomenon being investigated.
Early in the study it was recognised that the climatic and topographic diversity in the study area would likely preclude the use of large geographic areas that would meet statistical criteria for homogeneity. It was decided to employ climatic/ geographic regions that had basic similarities in the climatic and topographic setting. It was anticipated that these regions might require further sub-division to meet homogeneity criteria for use in regional frequency analysis.

\section{DESCRIPTION OF CLIMATIC/GEOGRAPHIC REGIONS}

Identification of climatologically-similar regions meant delineating geographic areas that had similar climatological and topographical characteristics. To assist in this effort, a literature review was conducted to examine region designations utilised in prior studies. This included a review of NOAA Atlas 2 ( Miller et al., 1973), studies of extreme precipitation in the Pacific Northwest (NWS, 1976, 1994) and prior regional frequency analyses conducted in mountain areas (Schaefer et al., 2002, 2006; Schaefer, 1990, 1989, 1997; Schaefer and Barker, 1997, 2000). Each of the region designations in these prior studies was based, to some extent, on the spatial distribution of mean annual precipitation and topographic characteristics, particularly the orientation of mountain ranges.

This information was augmented by analyses of the seasonality of 24-hour precipitation annual maxima. Those analyses revealed winter storms to dominate events in the Cascade Mountains and western Washington (Fig. 3a). Areas to the east are climatically far more variable, with seasonality characteristics showing a mixture of winter (Nov-Apr), spring-summer (May-Aug) and autumn (Sep-Oct) annual maxima (Figs. 3b, c, respectively).

Locally high gradients in statistical measures of storm characteristics were found where the Cascade Mountain foothills abut the arid and semi-arid lowlands in the Okanogan Valley and Columbia Basin. In addition, marked changes in statistical measures of the variability of 24-hour annual maxima precipitation data (Fig. 7) were observed in the foothill areas. A transition zone was used in this foothill area to provide for a smooth transition in the spatial mapping of precipitation at the boundary between adjacent climatic regions. Another transition zone was used near the Cascade Crest where the windward west face of the Cascade Mountains merges with the leeward eastern face of the Cascade Mountains. Four climatic regions (14, 77, 7 and 13) and two transition zones (154 and 147) for eastern Washington are described in the following sections. Six climatic regions $(5,151,142,32,31$, and 15$)$ were used to describe western Washington while four climatic regions 

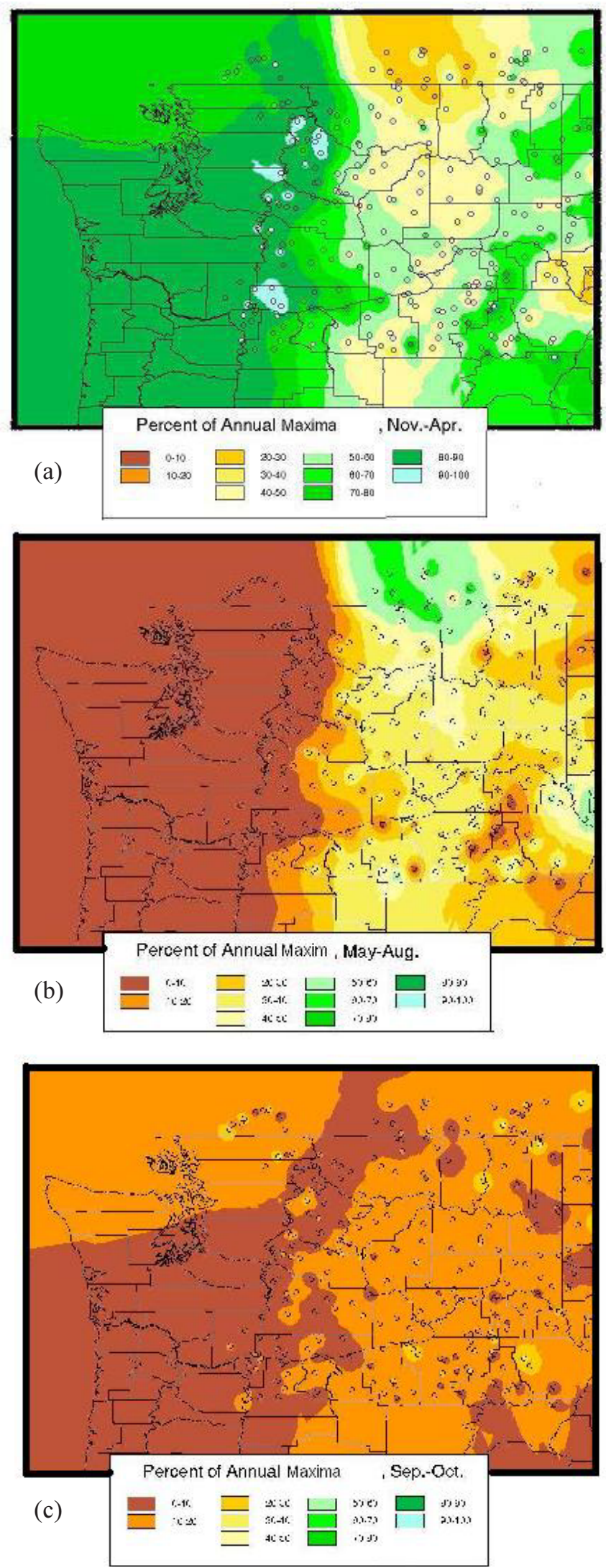

Fig. 3. (a) Frequency of 24-hour annual maxima for Washington study area: (a), winter (Nov-Apr), (b)spring-summer (May-Aug), (c) autumn (Sep-Oct). Class boundaries for regional frequency amounts were computer generated using inverse distance weighting.
(14, 77, 7, and 13) and two transition zones (154 and 147) were used for eastern Washington; these ten regions and the two transition zones are described below.

\section{CLIMATIC/GEOGRAPHIC REGIONS FOR} WASHINGTON STUDY AREA

Descriptions of climatic/geographic regions are listed below.

Region 5 - Coastal Lowlands - The lowlands along the west coast of Washington, Oregon and Vancouver Island that are open to the Pacific Ocean. The eastern boundary is either a generalised contour line of 1000 feet elevation, or the ridgeline of mean annual precipitation that separates the coastal lowlands from the interior lowlands, such as within the Aberdeen-Montesano gap.

Region 151 - Coastal Mountains West - The windward faces of the Olympic Mountains, Willapa Hills, Black Hills, Coastal Mountains in Oregon, and Vancouver Island Mountains in British Columbia above a generalised contour line of 1000 feet elevation. These areas are bounded to the west by the 1000 feet contour line, and bounded to the east by the ridgeline of mean annual precipitation near the crest of the mountain barrier.

Region 142 - Coastal Mountains East - The leeward faces of the Olympic Mountains, Willapa Hills, Coastal Mountains in Oregon, and Vancouver Island Mountains in British Columbia above a generalised contour line of 1000 feet elevation. These areas are bounded to the west by the ridgeline of mean annual precipitation near the crestline of the mountain barrier, and bounded to the east by the 1000 feet contour line. This also includes isolated mountain features such as the Black Hills.

Region 32 - Interior Lowlands West - The interior lowlands below a generalised contour line of 1000 feet elevation bounded to the east by the trough-line of mean annual precipitation through the Strait of Juan De Fuca, Puget Sound Lowlands and Willamette Valley. This is a zone of low orography where mean annual precipitation generally decreases from west to east.

Region 31 - Interior Lowlands East - The interior lowlands below a generalised contour line of 1000 feet elevation bounded to the west by the trough-line of mean annual precipitation through the Strait of Juan De Fuca, Puget Sound Lowlands and Willamette Valley. This is a zone of low orography where mean annual precipitation generally increases from west to east. 


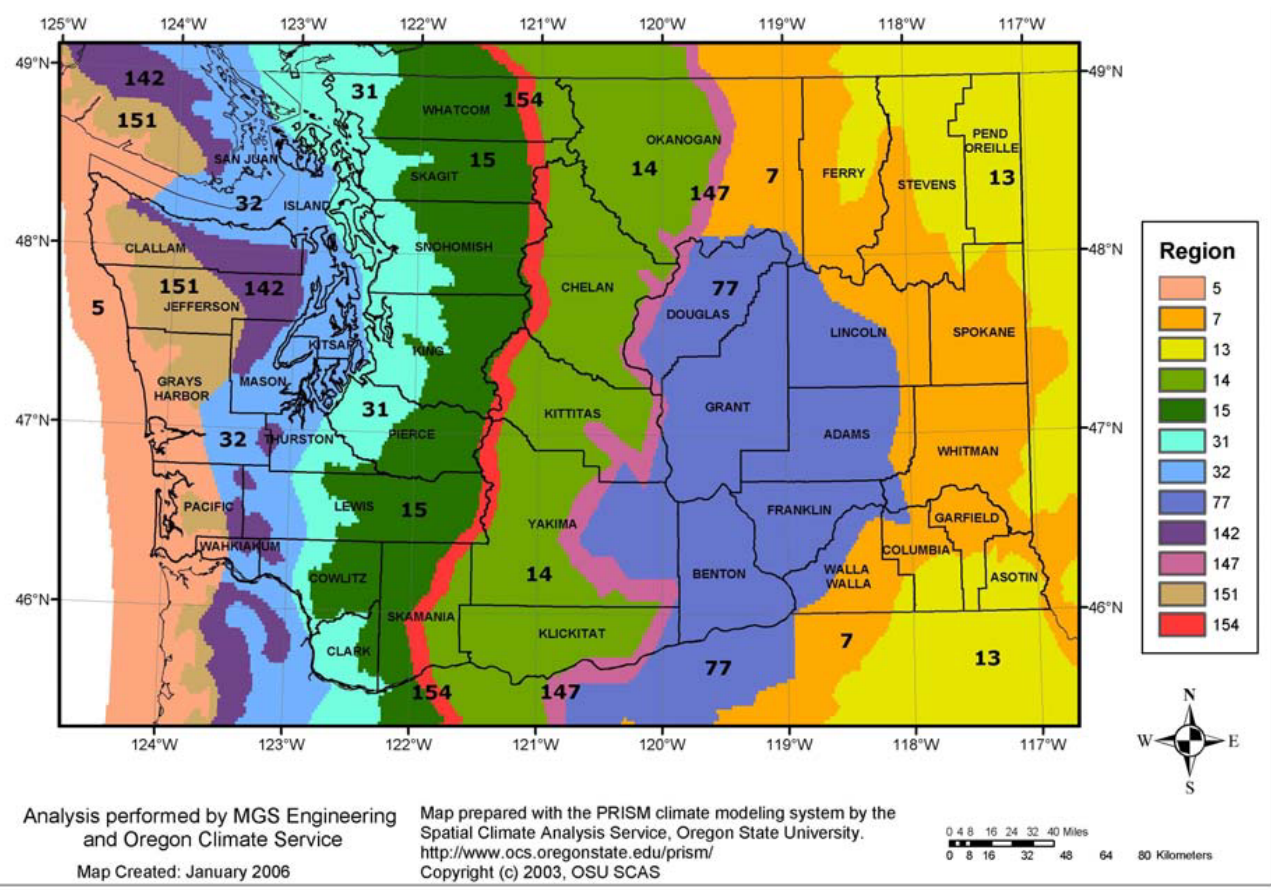

Fig. 4. Climatic/geographic regions and transition zones delineated for Washington State and surrounding sreas

Region 15 - West Slopes of Cascade Mountains - This region comprises the windward face of the Cascade Mountains in Washington, Oregon and British Columbia above a generalised contour line of 1000 feet elevation. The region is bounded to the east by the ridgeline of mean annual precipitation near the Cascade crest that forms the boundary with Region 14 located on the east slopes of the Cascade Mountains.

Zone 154 - Cascade Crest Transition Zone - This is a transition zone near the crest of the Cascade Mountains between the west and east slopes of the Cascade Mountains (Regions 15 and 14). The transition zone has a nominal width of about 6-miles and is used to provide a smooth transition in spatial mapping of precipitation in the Cascade Crest area.

Region 14 - East Slopes of Cascade Mountains - This region comprises mountain areas on the east slopes of the Cascade Mountains where precipitation annual maxima are produced predominantly by winter storm events (Fig. 3a). The region is bounded to the west by the ridgeline of mean annual precipitation that generally parallels the crest line of the Cascade Mountains. Region 14 is bounded to the east by the 14-inch contour of mean annual precipitation for locations north of the Methow River Valley and by the contour line of 12-inches means annual precipitation for areas to the south of the Methow River Valley.
Zone 147 - Cascade Foothills Transition Zone - This is a transition zone between the east slopes of the Cascade Mountains (Region 14) and arid and semi-arid areas to the east. The transition zone has a nominal width of about 6miles (based on recommendations from George Taylor, Oregon Climate Service). Region 147 is used to provide a smooth transition for L-moment ratio statistics and spatial mapping of precipitation between Regions 14 and 77, and Regions 14 and 7.

Region 77 - Central Basin - The Central Basin region comprises the Columbia Basin and adjacent low elevation (non-orographic) areas in central eastern Washington. It is bounded to the west by Region 14. The region is bounded to the north and east by the generalised (smoothed) contour line of 12-inches mean annual precipitation.

Region 7 - Okanogan, Spokane, Palouse - This region is a mixture of lowland areas of low to moderate relief and extensive valley areas between mountain barriers. This includes areas near Spokane, the Palouse, and areas along the Okanogan River. The region is bounded to the northwest by Region 14. It is bounded to the south and west by Region 77 , which generally conforms to the contour line of 12 inches mean annual precipitation at the eastern edge of the Central Basin. It is bounded to the northeast by the Kettle River Range and Selkirk Mountains at approximately the contour line of 22-inches mean annual precipitation. It is 
bounded to the southeast by the Blue Mountains also at the contour line of 22-inches mean annual precipitation.

\section{Region 13 - Northeastern Mountains and Blue Mountains}

- This region is composed of mountain areas in the easternmost part of Washington State where there is a significant orographic component to precipitation magnitudes. It includes portions of the Kettle River Range, Selkirk Mountains and Cabinet Mountains in the north-east, the Bitterroot Range to the East, and the Blue Mountains in the south-east corner of eastern Washington. Mean annual precipitation ranges from a minimum of 22-inches to over 70 -inches in the mountain areas. The western boundary of this region generally conforms to the contour line of 22inches mean annual precipitation.

\section{Regional growth curve}

Implicit in the definition of a homogeneous region in Lmoment regionalisation is the condition that all sites can be described by one probability distribution having common distribution parameters after the site data are rescaled by their at-site mean. Thus, all sites within a homogeneous region have a common regional magnitude-frequency curve that becomes site-specific after scaling by the at-site mean of the data from the specific site of interest. Thus,

$$
Q_{i}(F)=\hat{\mu}_{i} q(F)
$$

where $Q_{i}(F)$ is the at-site inverse Cumulative Distribution Function (CDF), $\hat{\mu}_{i}$ is the estimate of the population atsite mean, and $q(F)$ is the regional growth curve, regional inverse CDF. This is often called an index-flood approach to regional frequency analyses and was first proposed by Dalrymple (1960) and expanded by Wallis $(1980,1982)$.

\section{Forming homogeneous sub-regions}

Identification and formation of homogeneous regions is an iterative process. It was anticipated that the climatic regions defined here would require sub-division to meet homogeneity criteria. The methodology used herein for forming and testing proposed homogeneous sub-regions follows the procedures recommended by Hosking and Wallis (1997, 1993).

The basic approach is to propose homogeneous subregions (grouping of sites/gauges) based on the similarity of the physical/meteorological characteristics of the sites. L-moments (Hosking and Wallis $(1997,1993)$ are then used to estimate the variability and skewness of the pooled regional data and to test for heterogeneity as a basis for accepting or rejecting the proposed sub-region formulation.

In general, proposed homogeneous sub-regions can be formed by using some measure(s) of physical and/or climatological characteristics for assigning sites/gauges to sub-regions. Candidates for physical features (Miller et al., 1973; NWS, 1966, 1994) include such measures as: site elevation; elevation averaged over some grid size; localised topographic slope; macro topographic slope averaged over some grid size; distance from the coast or source of moisture; distance to sheltering mountains or ridgelines; and latitude or longitude. Candidate climatological characteristics include such measures as: mean annual precipitation; precipitation during a given season; seasonality of extreme storms; and seasonal temperature/dewpoint indices.

A review of the topographic and climatological characteristics in each region shows that each region already possesses several of the physical and climatological similarities listed above, and that only one measure, MAP, would be needed for grouping sites/gauges into homogeneous sub-regions within small ranges of MAP for each climatic region.

\section{HETEROGENEITY MEASURES OF PROPOSED} HOMOGENEOUS SUB-REGIONS

Heterogeneity measures have been developed by Hosking and Wallis $(1997,1993)$ as indicators of the amount of heterogeneity in the L-moment ratios for a collection of sites/ gauges. The statistics $\mathrm{H} 1$ and $\mathrm{H} 2$ measure the relative variability of observed $\mathrm{L}-\mathrm{Cv}$ and L-Skewness sample statistics and were used in the analyses of gauges/sites in each sub-region. Specifically, these measures compare the observed variability with that expected from a large sample drawn from a homogeneous region from the Kappa distribution (Hosking, 1997, 1988) having weighted average L-moment ratios that were observed in the sub-region. Initial recommendations from Hosking and Wallis (1997, 1993) were that regions with $\mathrm{H} 1$ and $\mathrm{H} 2$ values less than 1.00 were acceptably homogeneous. Values of $\mathrm{H} 1$ and $\mathrm{H} 2$ between 1.00 and 2.00 were possibly heterogeneous. Values greater than 2.00 indicated definite heterogeneity and that redefinition of the region and/or reassignment of sites/ gauges should be considered.

These heterogeneity criteria measure statistical heterogeneity from known distributions and do not account for variability that arises from other sources. Most cooperative precipitation measurement networks include gauges operated by various organisations and individuals that provide a varied level of quality control. Therefore, precipitation measurements often contain additional variability due to: gauges being moved during the many 
years of operation; frequent change of operators and level of diligence in timely measurement; missing data arising from inconsistent reporting; lack of attention to measurement precision; and localised site and wind condition changes over time due to building construction or growth of trees in the vicinity of the gauge. Recognising this additional variability, Wallis (1997) has suggested that for precipitation annual maxima, $\mathrm{H} 1$ values less than 2.00 may be considered acceptably homogeneous and $\mathrm{H} 1$ values greater than 3.00 would be indicative of heterogeneity. Both the $\mathrm{H} 1$ and $\mathrm{H} 2$ measures were used to assess the relative heterogeneity in proposed sub-regions.

ACCEPTANCE OF PROPOSED HOMOGENEOUS SUBREGIONS

When a proposed sub-region is found to satisfy homogeneity criteria, the regional L-moment ratios are then used to conduct goodness-of-fit tests (Hosking and Wallis, 1997, 1993) to assist in selecting a suitable probability distribution, and to estimate the parameters of the regional distribution. Examples of this type of approach are described for Washington State (Schaefer et al., 2002; Schaefer, 1990), southern British Columbia, and the Sierra Mountains in California. The basic approach adapted to this study is summarised below:

\section{Adopted methodology}

(1) Homogeneous sub-regions were created by assigning gauges within a climatic region to groups within a small range of mean annual precipitation;

(2) L-moment sample statistics for all gauges within each sub-region were calculated;

L-moment heterogeneity criteria were used to test proposed homogeneous sub-regions (Hosking and Wallis, 1997, 1993);

3) Mathematical predictors for describing the behaviour of regional L-Cv and L-skewness values as functions of mean annual precipitation within each climatic region were developed;

4) Goodness-of-fit tests were used to identify a suitable probability distribution for each regional growth curve;

5) The distribution parameters of the selected probability distribution for each sub-region were calculated using the regional values of L-Cv and L-skewness (from Step $4)$.

SYSTEMATIC VARIATION OF L-CV AND LSKEWNESS WITH MEAN ANNUAL PRECIPITATION

As described previously, climatic regions comprised numerous homogeneous sub-regions each with tightly controlled L-Moment ratios. A mathematical relationship was therefore needed to link the sub-regions and provide estimation of L-moment ratios L-Cv and L-Skewness across a climatic region. The relationships were developed in a manner to provide continuity with adjacent climatic regions. This approach had the additional benefit of eliminating or minimising discontinuities at the boundaries between the climatic regions. Recognising that the sub-regions were formed as groupings of gauges within a small range of mean annual precipitation (MAP), it was found that MAP was a suitable explanatory variable. The form of the equations varied slightly depending upon region and whether $\mathrm{L}-\mathrm{Cv}$ or L-Skewness was being considered. The three equations used were:

$$
\begin{aligned}
& \text { L-Moment Ratios }=\alpha e^{-\beta(M A P)}+\delta \\
& \text { L-Moment Ratios }=\alpha+\beta(L N[M A P]) \\
& \text { L-Moment Ratios }=\alpha M A P^{2}+\beta M A P+\delta
\end{aligned}
$$

A least squares solution was used to determine the alpha and beta parameters. For each region standardised root mean square error (RMSE) was also computed for the predictor equation to provide a measure of its goodness-of-fit. The resultant predictor equations for $\mathrm{L}-\mathrm{Cv}$ are listed in Table 3. The apparent anomaly in regional L-moments occurring in eastern Washington between the Cascade foothills, (Region 14), and the two adjoining regions to its east (7 and 77) are depicted graphically in Fig. 7.

\section{Analyses of 24-hour duration annual maxima}

Homogeneous sub-regions were formed as collections of gauges within small ranges of mean annual precipitation (MAP) within each of the climatic regions. The range of MAP was chosen so that about 10 to 15 gauges, 400 to 700 station-years of record, were included in each sub-region with each gauge having at least 15 years of record; this resulted in a total of 51 sub-regions at the 24-hour duration (Table 2). Record lengths at precipitation measurement stations varied from a minimum of 15 -years to over 100years, with nearly $50 \%$ of the stations having record lengths in excess of 50-years. Figure 6 depicts the number of stations with various ranges of record length.

The prominent spike in the number of eastern stations with record lengths in the range of 21-30 years is primarily due to the installation of SNOTEL stations in the 1970s.

The 154 transition zone was not included in Table 2 as its 


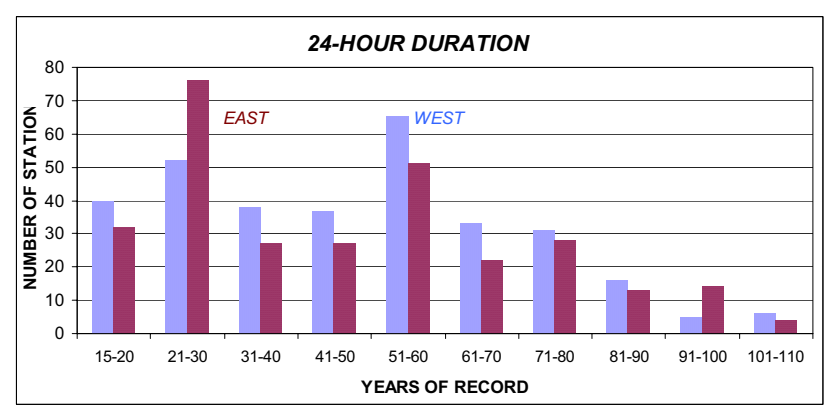

Fig. 6. Histogram of record lengths for 24-hour annual maxima

grid cells were populated as a weighted average of the predictor equations for regions 14 and 15, with weights based on the linear distance from the boundaries of the transition zone. The predictor equations for $\mathrm{L}-\mathrm{Cv}$ and $\mathrm{L}-$ skew converge at high MAP to identical values for regions 14 and 15 ; hence it is only in the least wet areas near the crest of the Cascade Mountains ( $\sim 80$ inches MAP for region $154)$ that the transition zone calculation actually becomes necessary, and even then it is only at the higher recurrence intervals that the difference is appreciable.

REGIONAL SOLUTIONS FOR L-MOMENT RATIOS, LCV AND L-SKEWNESS

Regional predictor equations for L-moment ratios were developed for groupings of sub-regions. It was found that a single predictor equation applicable to adjacent climatic subregions could be developed. All climatic regions had smooth exponential (or near exponential) decay functions for both L-CV and L-Skewness, with a regional asymptotic delta value controlled for each region by the maximum sub-region value of MAP. (For details see the specific reports for Eastern (Schaefer et al., 2006) ${ }^{2}$ and Western Washington (Schaefer et al., 2002).

A least squares solution was used to determine the alpha and beta parameters. Standardised root mean square error (RMSE) was also computed for the predictor equation for each region(s) to provide a measure of the goodness-of-fit of the predictor equation. The resultant predictor equations for L-Cv are listed in Table 3 and the apparent anomaly occurring for eastern Washington is graphically depicted in Fig. 7.

Cascade Foothills Transition Zone - Review of Fig. 7d reveals a marked break in the magnitudes of the variability measure L-Cv for the East Slopes of the Cascade Mountains (Region 14 and Transition Zone 147) relative to that in the arid and semi-arid regions further east (Regions 77, 7 and 13). Review of Figs. 3a, b, c shows that a sharp change in storm seasonality accompanies this distinctive change in

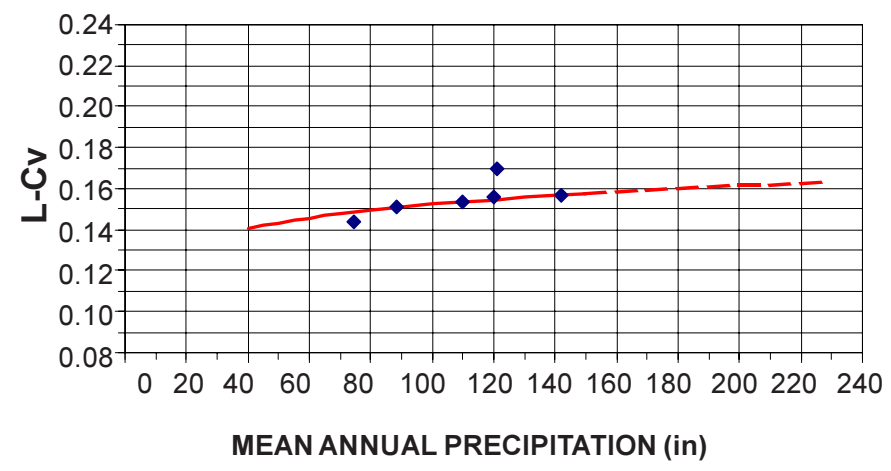

Fig. 7a. Predictor equation solutions of observed L-Cv for climatic regions 5 and 151 at 24-hour duration

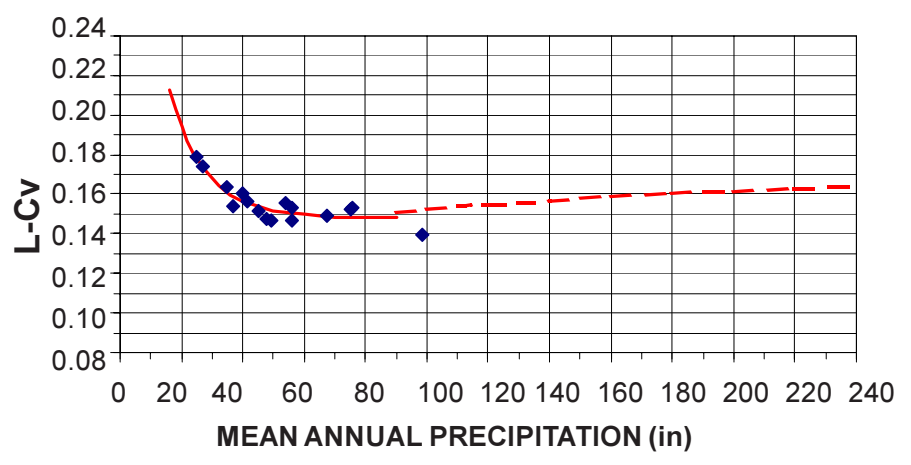

Fig. 7b. Predictor equation solutions of observed $L-C v$ for climatic regions 32 and 142 at 24-hour duration

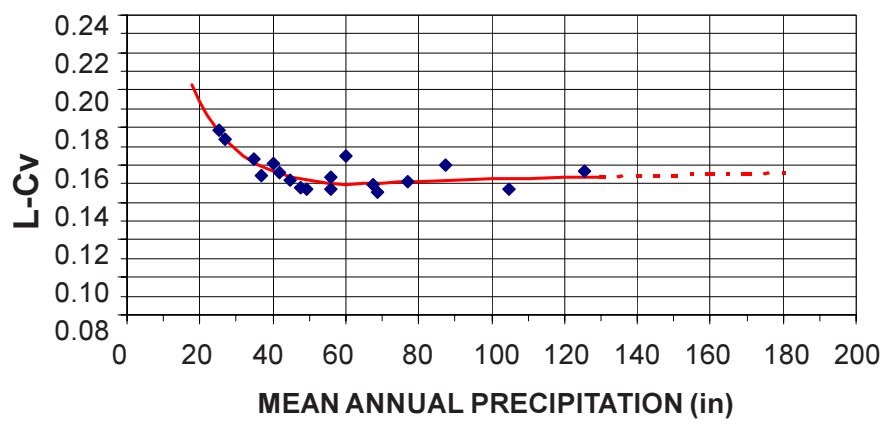

Fig. 7c. Predictor equation solutions of observed $L-C v$ for climatic regions 31 and 15 at 24-hour duration

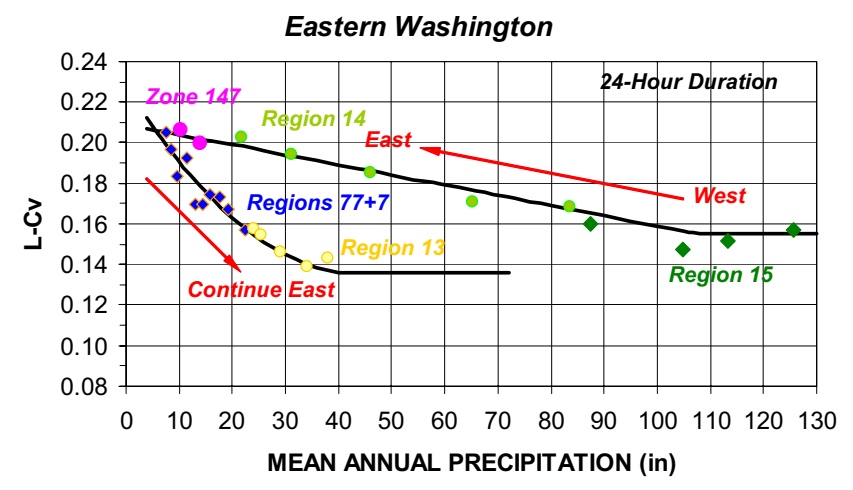

Fig. 7d. Predictor equation solutions of observed L-Cv for climatic regions in Eastern Washington at 24-hour duration 
J.R.Wallis, M.G. Schaefer, B.L. Barker and G.H.Taylor

Table 2. Number of sub-regions, gauges and station-years of record at the 24-hour duration annual maxima

\begin{tabular}{lccccc}
\hline Climatic regions & No. of sub-regions & Daily gauges & Hourly gauges & SNOTEL gauges & Station years of record \\
\hline 5 & 3 & 18 & 9 & 0 & 1328 \\
151 & 2 & 8 & 6 & 0 & 715 \\
142 & 3 & 20 & 6 & 1 & 1263 \\
32 & 6 & 39 & 17 & 0 & 2838 \\
31 & 7 & 45 & 16 & 0 & 3474 \\
15 & 6 & 24 & 28 & 19 & 2925 \\
14 & 7 & 44 & 14 & 0 & 3650 \\
Zone 147 & 2 & 13 & 5 & 0 & 1045 \\
77 & 4 & 38 & 7 & 0 & 2419 \\
7 & 5 & 41 & 17 & 25 & 2511 \\
13 & 6 & 55 & $\mathbf{1 3 2}$ & $\mathbf{7 1}$ & $\mathbf{2 6}$ \\
TOTAL & $\mathbf{5 1}$ & $\mathbf{3 4 5}$ & & $\mathbf{2 9 2}$ \\
\hline
\end{tabular}

Table 3. Predictor equations for L-Cv for 24-hour annual maxima

\begin{tabular}{|c|c|c|c|c|c|c|}
\hline Regions & Applicability & Alpha & Beta & Delta & Standardised RMSE & Equation No. \\
\hline $5-151$ & ALL & 0.0925 & 0.0130 & & $5.3 \%$ & $2 b$ \\
\hline $32-142$ & MAP $<75$-inches & 0.2500 & 0.0845 & 0.1480 & $3.2 \%$ & $2 \mathrm{a}$ \\
\hline $32-142$ & MAP $\geq 75$-inches & 0.0925 & 0.0130 & & $3.2 \%$ & $2 b$ \\
\hline $31-15$ & MAP. $<.60$-inches & 0.2500 & 0.0845 & 0.1480 & $3.5 \%$ & $2 \mathrm{a}$ \\
\hline $31-15$ & MAP $\geq 60$-inches & 0.1276 & 0.0054 & & $3.5 \%$ & $2 b$ \\
\hline 14 - zone 147 & MAP $<108$-inches & 0.0000 & -0.0005 & 0.2090 & $2.6 \%$ & $2 \mathrm{c}$ \\
\hline 14 & MAP $\geq 108$-inches & 0.0000 & 0.0000 & 0.1550 & & $2 \mathrm{c}$ \\
\hline $77-7-13$ & MAP $\leq 40$-inches & 0.0000475 & -0.0042 & 0.2281 & $3.1 \%$ & $2 \mathrm{c}$ \\
\hline 13 & MAP $>40$-inches & 0.0000 & 0.0000 & 0.1360 & & $2 \mathrm{c}$ \\
\hline
\end{tabular}

the magnitude of $\mathrm{L}-\mathrm{Cv}$ at the Cascade foothill boundary with the three more easterly regions. Specifically, 24-hour precipitation annual maxima are predominately produced by winter storms on the east slopes of the Cascade Mountains and the 24-hour annual maxima in areas further east are produced by a mixture of winter, spring and summer storms (Figs. $21 \mathrm{a}, \mathrm{b}, \mathrm{c}$ ). These sharp climatic changes provided the impetus for using a transition zone (Transition Zone 147) in the Cascade foothills area.

Skewness measures are highly variable for the record lengths commonly available for precipitation-frequency analysis. This greater sampling variability is exhibited in larger RMSE values for the predictor equations for LSkewness (Table 4). Regional predictor equations for L-

Table 4. Predictor equations for L-Skewness for 24-hour annual mMaxima

\begin{tabular}{|c|c|c|c|c|c|c|}
\hline Regions & Applicability & Alpha & Beta & Delta & Standardised RMSE & Equation No. \\
\hline $5-151$ & MAP $<150$ inches & 0.0930 & 0.0130 & & $13.7 \%$ & $2 b$ \\
\hline $5-151$ & MAP $\geq 150$ inches & 0.1580 & 0.0000 & & & $2 b$ \\
\hline $32-142$ & MAP $<70$-inches & 0.1500 & 0.0400 & 0.1400 & $14.2 \%$ & $2 \mathrm{a}$ \\
\hline $32-142$ & $\begin{array}{l}70 \text { inches } \leq \text { MAP } \\
<150 \text {-inches }\end{array}$ & 0.0930 & 0.0130 & & & $2 b$ \\
\hline $32-142$ & MAP $>150$ _inches & 0.1580 & 0.0000 & & & $2 b$ \\
\hline $31-15$ & All Areas & 0.1300 & 0.0400 & 0.1580 & $9.8 \%$ & $2 \mathrm{a}$ \\
\hline $\begin{array}{l}14 \text {-zone } 147 \\
77-7-13\end{array}$ & All Areas & 0.1150 & 0.0400 & 0.1580 & $7.4 \%$ & $2 \mathrm{a}$ \\
\hline
\end{tabular}




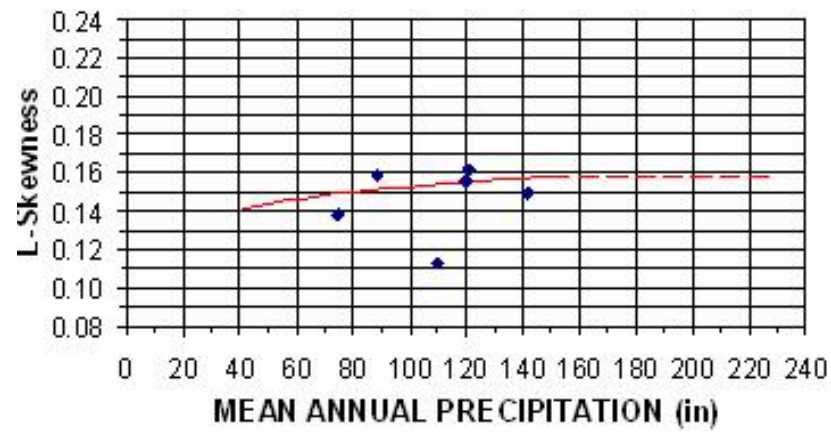

Fig. 8a. L-skewness for 24-hour precipitation, regions 5 and 151, eestern Washington

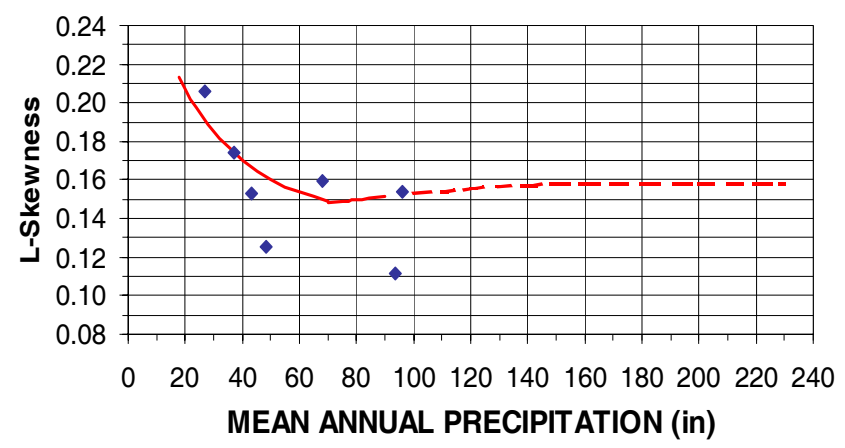

Fig. 8b. L-skewness for 24-hour precipitation, regions 32 and 142, eestern Washington

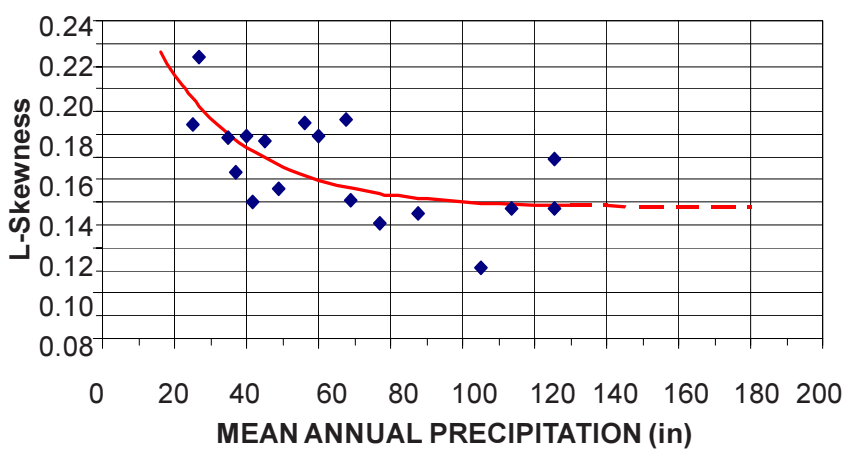

Fig. 8c. L-skewness for 24-hour precipitation, regions 31 and 15, western Washington

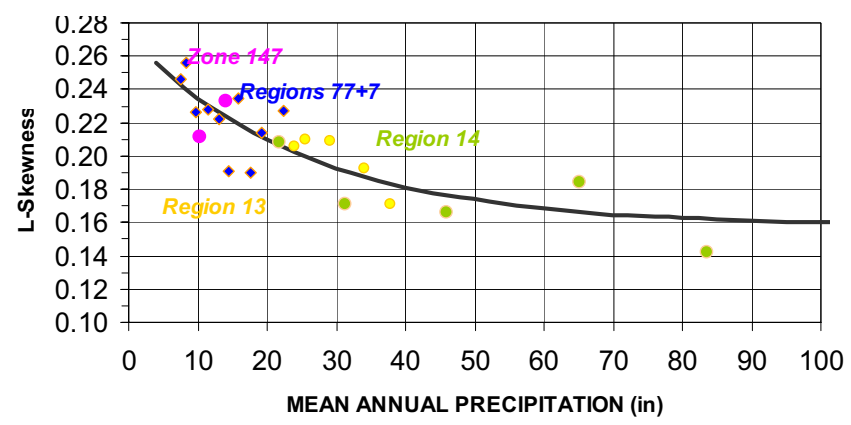

Fig. 8d. L-skewness for 24-hour precipitation, regions and zones of eastern Washington
Skewness were developed as described above for L-Cv. The predictor equations for L-Skewness are listed in Table 4 and graphed in Fig. 8

HETEROGENEITY MEASURES, 24-HOUR DURATION Heterogeneity measures $\mathrm{H} 1$ and $\mathrm{H} 2$ (Hosking and Wallis, 1997, 1993) were used to judge the relative heterogeneity in the proposed sub-regions for L-Cv and L-Skewness, respectively. Computation of $\mathrm{H} 1$ and $\mathrm{H} 2$ values for the various sub-regions indicated that nearly all sub-regions were acceptably homogeneous (Table 5). In cases where computed heterogeneity measures exceeded acceptance criteria, the excursions were generally minor. In summary, mean annual precipitation was an excellent explanatory variable for describing the variability of $\mathrm{L}-\mathrm{Cv}$ and LSkewness across the study area.

\section{IDENTIFICATION OF REGIONAL PROBABILITY DISTRIBUTION, 24-HOUR DURATION}

One of the primary tasks in the regional analyses was to identify the best probability distribution for describing the behaviour of the annual maxima data. Accordingly, a goodness-of-fit test statistic (Hosking and Wallis $(1997,1993)$ was computed for each sub-region for use in identifying the best three-parameter distribution. Using the L-moment-based test statistic, the Generalised Extreme Value (GEV) distribution (Schaefer et al., 2002, 2006) was identified most frequently as the best three-parameter probability model (Table 5).

Plots of regional L-Skewness and L-Kurtosis values for the eastern and western sub-regions at the 24-hour duration are shown in Fig. 9. Nearness to the GEV distribution is clearly evident and consistent with the goodness-of-fit test results listed in Table 5.

The GEV is a very suitable distribution for estimation of precipitation quantiles out to the 500-year recurrence interval. If quantile estimates are desired for more extreme events than the 500-year recurrence interval, it would be worthwhile to refine the selection of the regional probability distribution. Given this consideration, it was decided to use the four-parameter Kappa (Hosking and Wallis, 1997; Hosking, 1988), distribution, which can mimic the GEV and produce a variety of regional growth curves immediately around the GEV. The inverse form of the Kappa distribution is:

$$
q(F)=\xi+\frac{\alpha}{\kappa}\left\{1-\left(\frac{1-F^{h}}{h}\right)^{\kappa}\right\}
$$


J.R.Wallis, M.G. Schaefer, B.L. Barker and G.H.Taylor

Table 5. Results of heterogeneity and goodness-of-fit tests for 24-hour

\begin{tabular}{|c|c|c|c|c|}
\hline Climatic regions & No. of sub-regions & $\begin{array}{l}\text { Homogeneous sub-regions } \\
H 1 \leq 2.00\end{array}$ & $\begin{array}{l}\text { Homogeneous sub-regions } \\
\text { H2 } \leq 1.00\end{array}$ & $\begin{array}{l}\text { Sub-regions accepting } \\
G E V \text { distribution }\end{array}$ \\
\hline 5151 & 5 & 3 & 4 & 5 \\
\hline $142-32$ & 9 & 6 & 7 & 8 \\
\hline $31-15$ & 13 & 13 & 11 & 13 \\
\hline 14 -zone 147 & 7 & 7 & 6 & 5 \\
\hline $77-7-13$ & 15 & 14 & 12 & 14 \\
\hline TOTAL & 22 & 21 & 18 & 19 \\
\hline
\end{tabular}
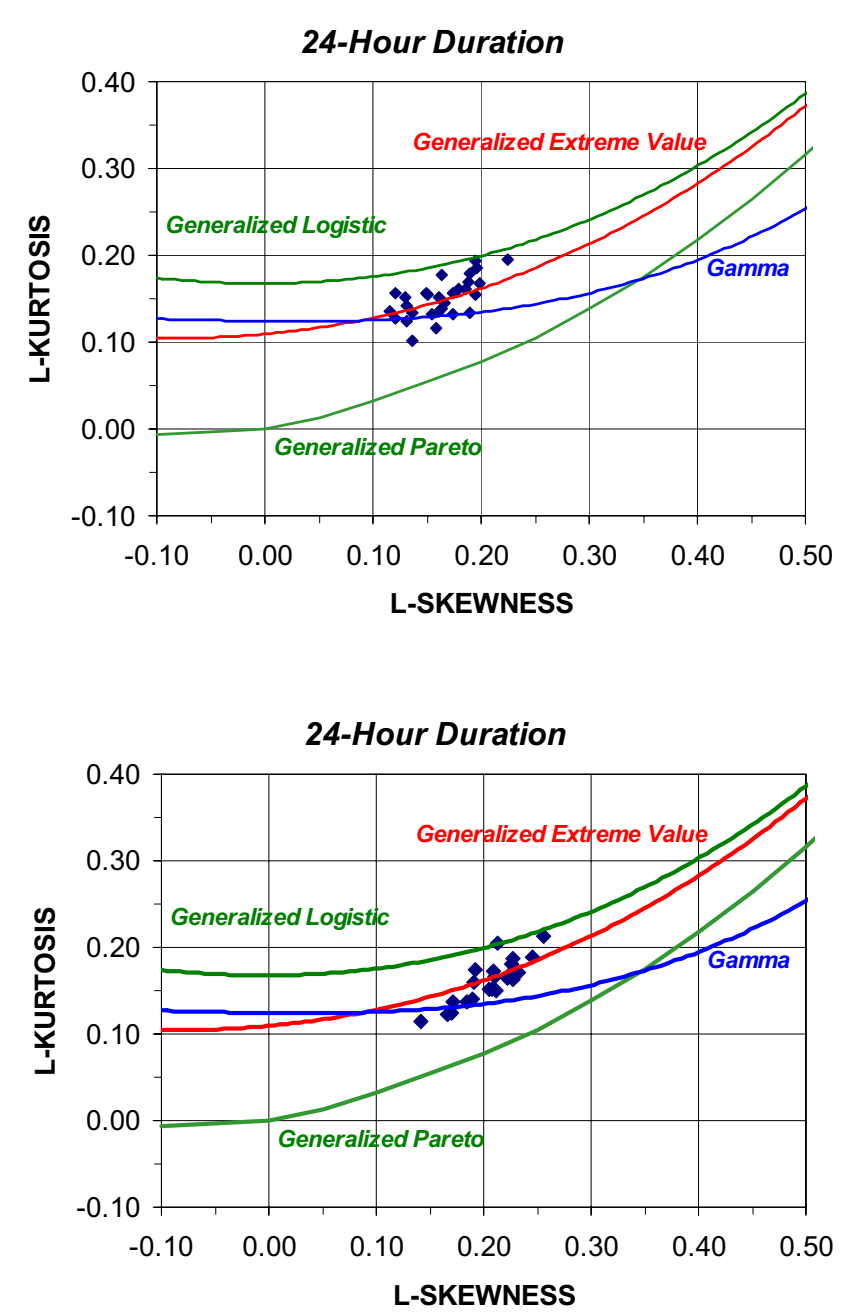

Fig. 9. L-moment ratio plot for all western (top) and eastern (below) sub-regions at 24-hour duration

where $\xi, \alpha$, are location and scale parameters, and $\kappa$, and $h$ are shape parameters respectively.

An $h$ value of zero leads to the GEV distribution, an $h$ value of 1 produces the Generalised Pareto (GP) and an $h$ value of -1 produces the Generalised Logistic (GL) distribution. Thus, positive values of $h$ produce regional growth curves that are flatter than the GEV, and negative values of $h$ produce steeper regional growth curves. Minor adjustments of $h$ near a zero value (GEV) allow fine-tuning of the regional growth curves. This minor adjustment of the $h$ value becomes important only for the estimation of very rare quantiles, while leaving the lesser quantiles unchanged.

To solve for an appropriate $h$ value, a hierarchical approach (Fiorentino, 1979) was taken wherein the shape parameter $h$ was computed as the average value from the group of sub-region solutions. An average value of 0.004 was computed with a standard error of estimation of about \pm 0.064 for the eastern Washington study area. This compares with an $h$ value of -0.05 found in the previous studies in western Washington (Schaefer et al., 2002), eastern British Columbia (Schaefer 1997) and eastern Oregon (Schaefer and Barker, 1997). A nominal $h$ value of -0.05 was adopted for eastern Washington; this is consistent with the findings of the previous studies and within one standard deviation of the sample average. This produces a regional growth curve slightly steeper than the GEV for very rare events and essentially matches the GEV out to about the 500-year recurrence interval.

\section{Analyses of 2-hour duration annual maxima}

As in the analysis of 24-hour annual maxima, homogeneous sub-regions at the 2-hour duration were formed as collections of gauges within small ranges of mean annual precipitation (MAP) within each of the climatic regions. The range of MAP was chosen so that about 8 to 12 gauges, 300 to 450 station-years of record, were included in each sub-region with each gauge having at least 15-years of record. This resulted in a total of 10 sub-regions for the 2hour duration (Table 6). Record lengths at precipitation measurement stations varied from a minimum of 15 -years to near 60 -years, with nearly $50 \%$ of the stations having 
Regional precipitation-frequency analysis and spatial mapping for 24-hour and 2-hour durations for Washington State

Table 6. Number of sub-regions, gauges and station-years of record for 2-hour duration annual maxima

\begin{tabular}{lccc}
\hline Climatic regions & $\begin{array}{l}\text { No. of } \\
\text { sub-regions }\end{array}$ & Hourly gauges & $\begin{array}{l}\text { Station years } \\
\text { of record }\end{array}$ \\
\hline $5-151$ & 2 & 19 & 721 \\
$142-32$ & 4 & 27 & 1,101 \\
$31-15$ & 7 & 63 & 2,424 \\
14 & 3 & 19 & 763 \\
Zone 147 & 1 & 8 & 396 \\
77 & 1 & 13 & 508 \\
7 & 3 & 19 & 814 \\
13 & 2 & 24 & 854 \\
TOTAL & 23 & 192 & 7,581 \\
\hline
\end{tabular}

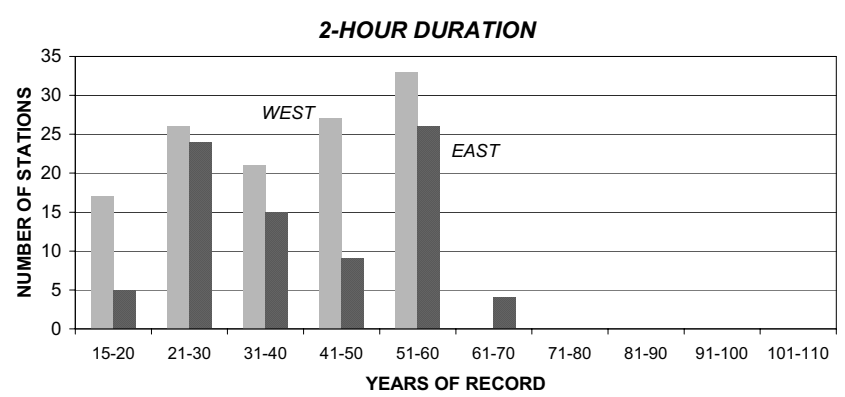

Fig. 10. Histogram of station record lengths for 2-hour annual maxima

record lengths in excess of 40-years. Figure 10 depicts the number of stations within various ranges of record length.

\section{REGIONAL SOLUTIONS FOR L-MOMENT RATIOS, L-} CV AND L-SKEWNESS

Regional predictor equations for L-moment ratios at the 2hour duration were developed in the same manner as that for the 24-hour duration. The resultant predictor equations for L-Cv are listed in Table 7 and depicted graphically in Fig. 11. The predictor equation for L-Skewness is listed in Table 8 and shown in Fig. 12.

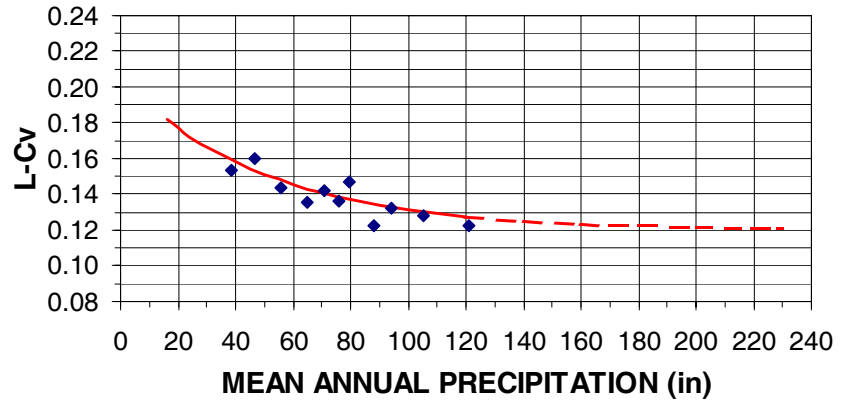

Fig. 11a. Predictor equation solutions of observed L-Cv for climatic regions $5,151,31$ and 15 at 2-hour duration

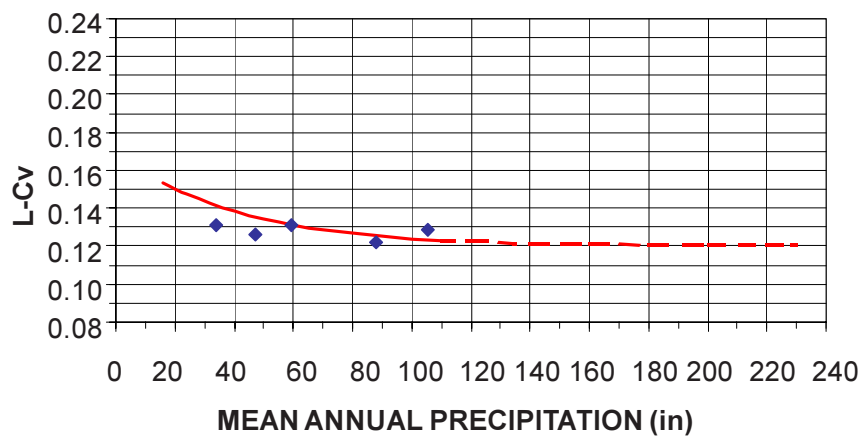

Fig. $11 \mathrm{~b}$. Predictor equation solutions of observed L-Cv for climatic regions 142 and 32 at 2-hour duration

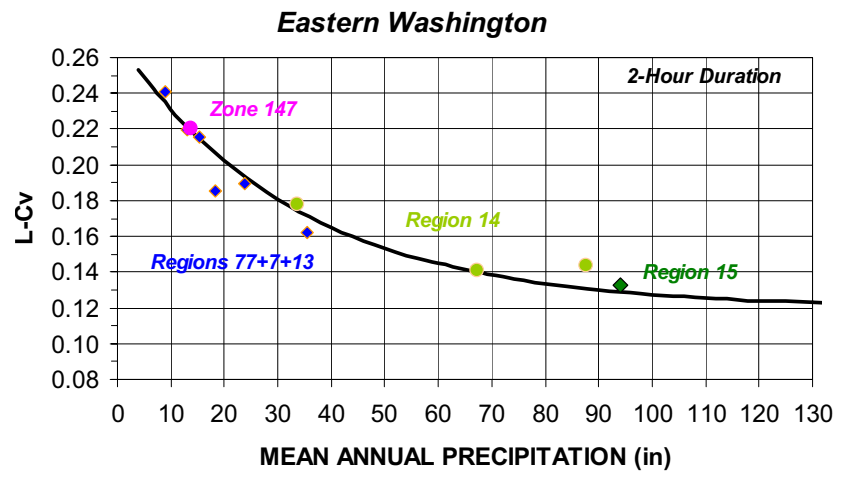

Fig. $11 \mathrm{c}$. Predictor equation solutions of observed L-Cv for climatic regions in eastern Washington at 2-hour duration

Table 7. Predictor equations for $\mathrm{L}-\mathrm{Cv}$ for 2-hour annual maxima

\begin{tabular}{llccccc}
\hline Regions & Applicability & Alpha & Beta & Delta & Standardised RMSE & Equation No. \\
\hline $5-151$ & All Areas & 0.0850 & 0.0200 & 0.1200 & $4.6 \%$ & $2 \mathrm{a}$ \\
$142-32$ & All Areas & 0.0500 & 0.0250 & 0.1200 & $7.9 \%$ & $2 \mathrm{a}$ \\
$31-15$ & All Areas & 0.0850 & 0.0200 & 0.1200 & $4.6 \%$ & $2 \mathrm{a}$ \\
$14-$ zone 147 & All Areas & 0.1500 & -0.0300 & 0.1200 & $5.1 \%$ & $2 \mathrm{c}$ \\
$77-7-13$ & & & & & & \\
\hline
\end{tabular}


J.R.Wallis, M.G. Schaefer, B.L. Barker and G.H.Taylor

Table 8. Predictor equations for L-Skewness for 2-hour annual maxima

\begin{tabular}{|c|c|c|c|c|c|c|}
\hline Regions & Applicability & Alpha & Beta & Delta & Standardised RMSE & Equation No. \\
\hline \multicolumn{7}{|l|}{$5-151$} \\
\hline $142-32$ & All Areas & 0.1800 & 0.0250 & 0.1700 & $15.7 \%$ & $2 \mathrm{a}$ \\
\hline $31-15$ & & & & & & \\
\hline $\begin{array}{l}14-\text { zone } 147 \\
77-7-13\end{array}$ & All Areas & 0.1900 & 0.0250 & 0.1700 & $10.3 \%$ & $2 \mathrm{a}$ \\
\hline
\end{tabular}
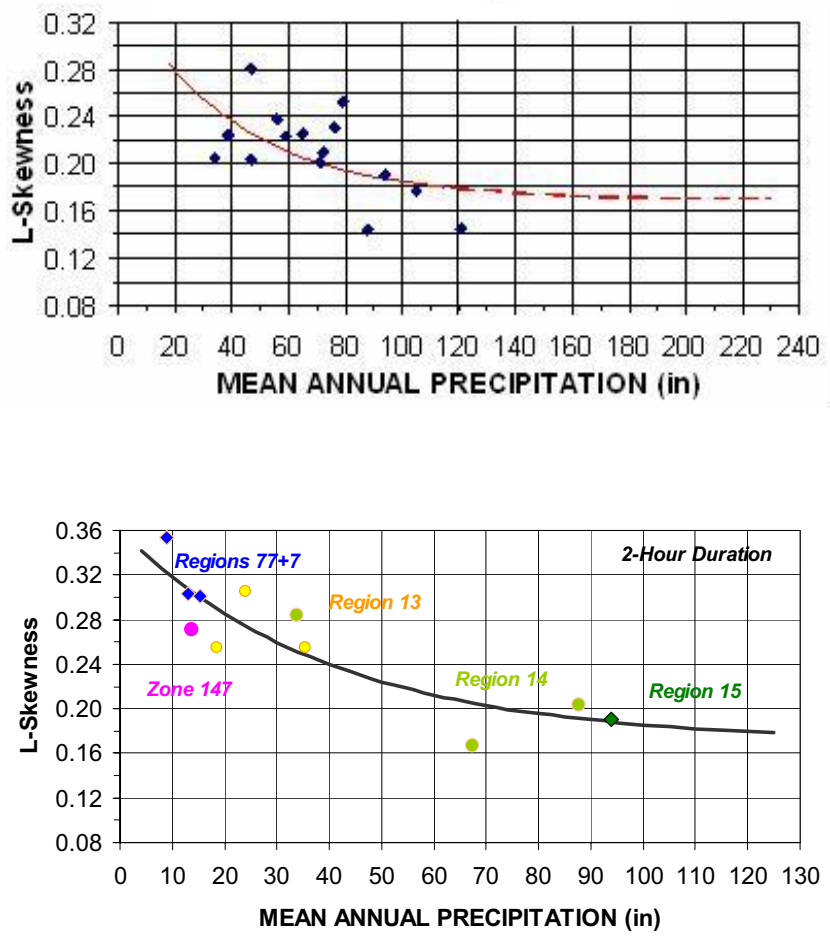

Fig. 12. Predictor equation solutions of observed L-skewness for all climatic regions in western (top) and eastern (below)Washington at 2-hour duration
There is greater variability in the L-skewness measures than for L-Cv. L-skewness measures are inherently more variable, particularly for the sample sizes of precipitation annual maxima that are commonly available. However, the general form of the solution curve is consistent with behaviour seen at the 24-hour duration and in other regional precipitation studies where the L-skewness values converge to some limiting value for sites with very high mean annual precipitation.

\section{HETEROGENEITY MEASURES, 2-HOUR DURATION}

Heterogeneity measures $\mathrm{H} 1$ and $\mathrm{H} 2$ (Hosking and Wallis (1997, 1993) were used to judge the relative heterogeneity in the proposed sub-regions for L-Cv and L-Skewness, respectively. Computation of $\mathrm{H} 1$ and $\mathrm{H} 2$ values for the various sub-regions indicated the majority of sub-regions were acceptably homogeneous (Table 9). Where computed heterogeneity measures exceeded acceptance criteria, the excursions were generally minor. As was the case for the 24-hour duration, mean annual precipitation was found to be a suitable explanatory variable for describing the variability of L-Cv and L-Skewness across the study area.

Table 9. Results of heterogeneity and goodness-of-fit tests for 2-hour duration

\begin{tabular}{lcccc}
\hline Climatic regions & No. of sub-regions & $\begin{array}{l}\text { Homogeneous sub-regions } \\
H 1 \leq 2.00\end{array}$ & $\begin{array}{l}\text { Homogeneous sub-regions } \\
H 2 \leq 1.00\end{array}$ & $\begin{array}{l}\text { Sub-regions accepting } \\
\text { GEV distribution }\end{array}$ \\
\hline $5-151$ & 2 & 1 & 1 & 2 \\
$142-32$ & 4 & 4 & 2 & 4 \\
$31-15$ & 7 & 5 & 7 & 6 \\
$14-$ Zone 147 & 4 & 3 & 4 & 4 \\
$77-7-13$ & 6 & 5 & $\mathbf{1 8}$ & 6 \\
TOTAL & $\mathbf{2 3}$ & $\mathbf{1 8}$ & $\mathbf{2 2}$ \\
\hline
\end{tabular}




\section{IDENTIFICATION OF REGIONAL PROBABILITYY}

\section{DISTRIBUTION, 2-HOUR DURATION}

The Generalised Extreme Value (GEV) distribution was identified most frequently as the best three-parameter probability model (Table 9) using the L-moment based test statistic for goodness-of-fit. Plots of regional L-Skewness vs. L-Kurtosis values for the western and eastern sub-regions at the 2-hour duration are shown in Fig.13. Most data pairs plot nearest the GEV distribution, with the centroid being slightly above, slightly more kurtotic, than the GEV distribution.

As was the case for the 24-hour duration, the GEV is a suitable distribution for estimation of precipitation quantiles out to the 500-year recurrence interval. If quantile estimates are desired for events more extreme than the 500-year recurrence interval, it would be worthwhile to utilise the four-parameter Kappa distribution and to refine the selection of the $h$ parameter. To solve for an appropriate $h$ value, a hierarchical approach (Fiorentino, 1979) was taken wherein the shape parameter $h$ was computed as the median value
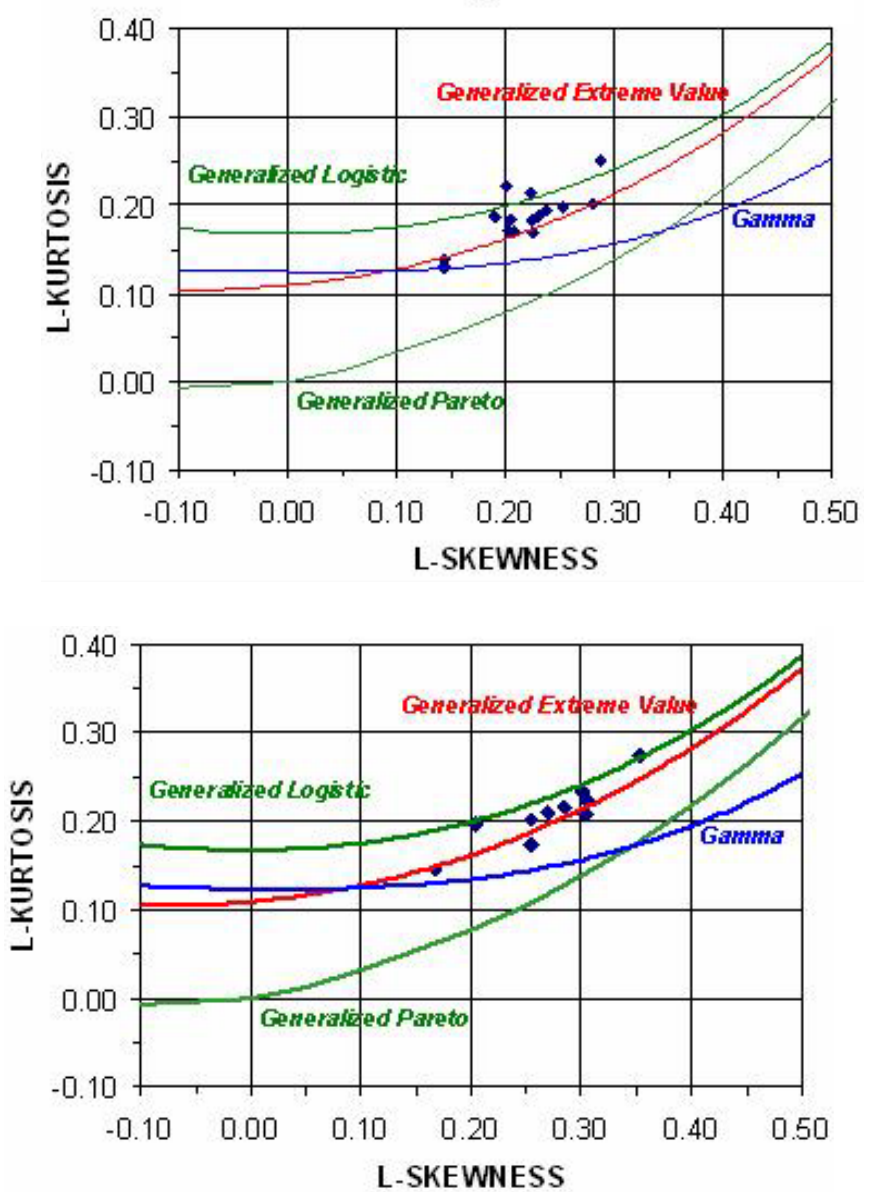

Fig. 13. L-moment ratio plot for western (top) and eastern (below) Washington sub-regions at 2-hour duration

from the group of sub-region solutions. A median value of 0.190 was computed with a standard error of estimation of approximately \pm 0.115 for the eastern Washington study area. Based on this information, a nominal $h$ value of -0.15 was adopted, which matches the value for western Washington (Schaefer et al., 2002) and is well within one standard deviation of the eastern sample value. This produces a regional growth curve somewhat steeper than the GEV for very rare events and essentially matches the GEV distribution up to about the 100-year recurrence interval.

\section{Precipitation magnitude-frequency estimates for gauged sites}

The first step in developing a site-specific precipitation magnitude-frequency curve is to compute the regional growth curve. The findings described above provide the information necessary for developing the regional growth curve for the 24-hour and 2-hour durations. Specifically, the first three parameters of the Kappa distribution $(\xi, \alpha$, and $\kappa$ ) are solved (Hosking and Wallis (1997, 1993) using a mean of unity and the applicable regional values of $\mathrm{L}-\mathrm{Cv}$ and L-Skewness as indicated in Tables 3, 4 and Tables 7, 8. The fourth parameter $(h)$ of the Kappa distribution is set to the regional average value applicable to the selected duration. Equation 3 is then used to describe the regional growth curve. The site-specific precipitation-frequency curve is obtained by scaling the regional growth curve by the at-site mean. For gauged sites, the at-site mean $(\mu)$ can be computed from the gauge mean $(\bar{x})$ based on the correction factors $\left(C_{n o p}\right)$ in Table 10. A correction factor is needed to adjust the gauge sample mean to account for reporting precipitation measurements at fixed time periods rather as the maximum values within a fixed duration.

Table 10. Correction factors $\left(C_{\text {nop }}\right)$ to adjust gauge sample statistics

Gauge type Duration
2-hour 24-hour

Regions 14 - zone 147

Daily and SNOTEL gauges

$\mathrm{n} / \mathrm{a}$

1.11

Regions $77-7-13$

Daily and SNOTEL gauges

$\mathrm{n} / \mathrm{a}$

1.08

Western Washington

Daily and SNOTEL gauges

$\mathrm{n} / \mathrm{a}$

1.13

Automated gauge: hourly reporting

1.04

Automated gauge:15-min reporting 
The at-site mean is computed from the gauge mean as:

$$
\hat{\mu}=C_{n o p}(\bar{x})
$$

where the correction factor $\left(C_{\text {nop }}\right)$ varies with the length of the observational period (i.e. 2-hours and 24-hours). A correction factor of 1.13 has been estimated from theoretical considerations (Weiss, 1964) and also been found in numerous studies (Miller et al., 1973). The value of 1.13 is commonly taken as a standard in humid environments subjected to numerous storms each year where the typical duration of storms significantly exceeds the observational period.

In arid and semi-arid areas there may be few noteworthy storms each year and the duration of the storms may be significantly less than the length of the daily observational period. In these cases, the correction factor for converting from maximum daily statistics to maximum 24-hour precipitation statistics may be something less than the conventional value of 1.13. A separate investigation was conducted to determine an appropriate correction factor for use with daily gauges because many storms have durations less than 24-hours in the arid and semi-arid areas of eastern Washington. Correction factors for daily measurements in eastern Washington were obtained by comparison of gauge mean values at sites having both daily and hourly gauges for a common period of measurement (years). This allowed direct comparisons to be made of the computed gauge mean values. The results of these analyses are listed in Table 10 and gauge means for daily annual maxima and 24-hour annual maxima are plotted in Fig. 14.

This procedure can be explained by an example using an existing gauged site. Spokane Airport has an automated gauge and is located in Region 7 (Okanogan, Spokane, and Palouse). The mean annual precipitation for the site is 17.0inches. For the 24-hour duration, the regional value of L-

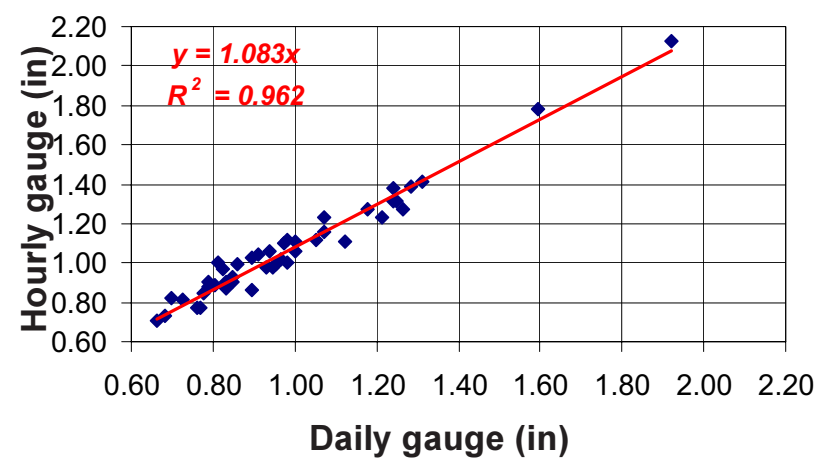

Fig. 14. Comparison of gauge mean values for co-located daily and hourly gauges for a common reporting period for Regions 77, 7 and 13.
$\mathrm{Cv}$ is 0.170 , which is obtained from Eqn. $2 \mathrm{~b}$ and parameter values from Table 3. The regional value of L-Skewness is 0.216 , which is obtained from Eqn. $2 \mathrm{a}$ and parameter values from Table 4 . The regional value of the $h$ parameter is -0.05 for the 24 -hour duration. Using a mean value of unity, the solution for the four parameters of the Kappa distribution Hosking and Wallis, 1997; Hosking, 1988), yields:

$$
\xi=0.8573, \alpha=0.2226, \kappa=-0.0823 \text {, and } h=-0.05 \text {. }
$$

Use of Eqn. 3 yields the regional growth curve depicted in Fig. 15. Spokane Airport has an hourly gauge with a gauge mean of 1.06-inches for the 24-hour duration for 54-years of record. Use of Eqn. 4 with a correction factor of 1.00 for the 24-hour duration yields an at-site mean value of 1.06inches. The at-site precipitation magnitude-frequency curve is obtained by scaling the regional growth curve by the atsite mean and is depicted in Fig. 15b. The observed 24hour annual maxima for the Spokane Airport site for the period from 1948-2003 are also depicted in Fig. 15b for a comparison of the regional solution with the observed annual maxima. These computations are incorporated in the precipitation spatial mapping products that are described in the following sections.
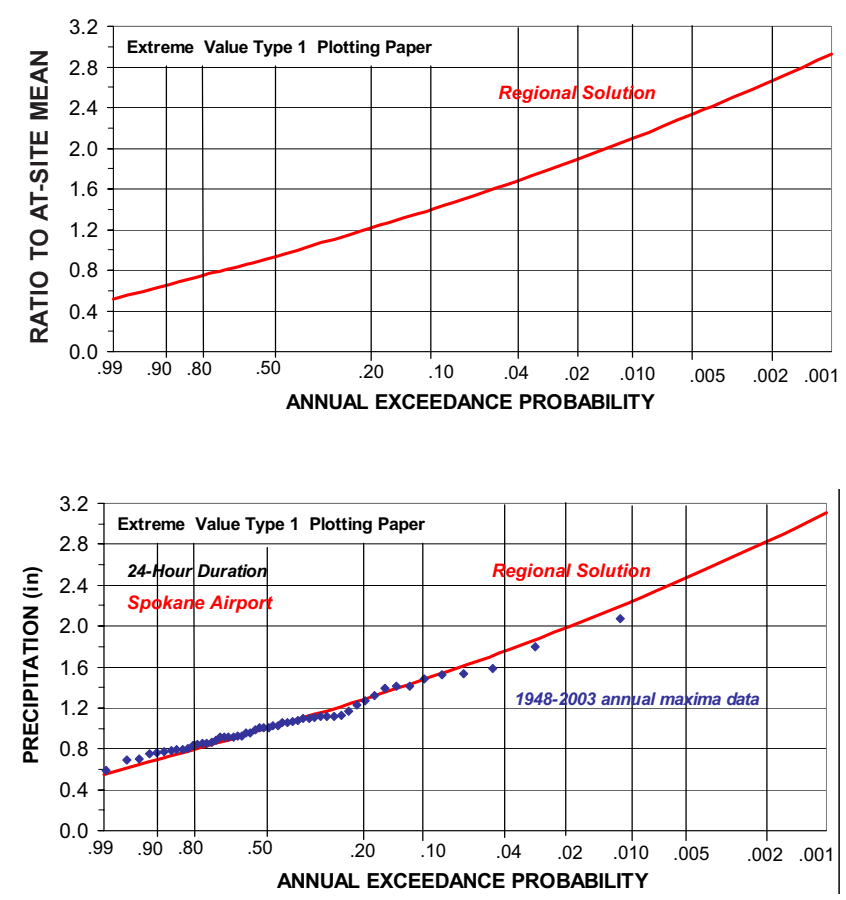

Fig. 15. Regional growth curve (top) and precipitation magnitudefrequency curve (bottom) for Spokane Airport for 24-Hour duration 


\section{Spatial mapping or precipitation- frequency information}

Products from the PRISM model (Daly et al., 2002) operated by Oregon Climate Service were used in conducting spatial mapping of precipitation for selected recurrence intervals. Grided datasets and isopluvial maps were prepared for the 2-year, 10-year, 25-year, 50-year and 100-year recurrence intervals for the 24-hour and 2-hour durations. A gridded dataset and isopluvial map were also prepared for the 6month (twice yearly) recurrence interval for the 24-hour duration, which is needed for some water quality applications. Precipitation estimates for the 6-month and 2year recurrence intervals were converted from annual maxima to partial duration series equivalents (Stedinger et al., 1992) using the conversion developed by Langbein (1949). This was done to improve the frequency estimates for common events and to be consistent with past mapping products produced by the National Weather Service (Miller et al., 1973).

The spatial mapping of precipitation for selected recurrence intervals is dependent upon the production of two key components in addition to the regional precipitationfrequency information. The first is the spatial mapping of at-site means (station mean values, also called mean annual maxima). Grid-cell values of at-site means are used to scale dimensionless magnitude-frequency relationships to obtain precipitation estimates for the recurrence interval of interest. The second component required is the spatial mapping of regional statistical parameters. This provides L-moment ratio statistics L-Cv and L-Skewness applicable to each grid-cell in the study area domain; these are used to determine the probability distribution parameters for describing the magnitude-frequency relationship applicable to each gridcell. Thus, the spatial mapping of at-site means and the spatial mapping of regional statistical parameters are the primary work products needed for isopluvial mapping.

\section{MEAN ANNUAL PRECIPITATION}

The gridded dataset of mean annual precipitation provides a basis for spatial mapping of both at-site means and Lmoment statistics and is, therefore, an important element of this project. An analysis of mean annual precipitation for the period from 1971 to 2000 has been completed for the study area by Oregon Climate Service using the PRISM model (Daly et al., 2002; Spatial Climate Analysis Service, 2005). The resultant map, used in this study, provides digital values of mean annual precipitation on a gridded latitudelongitude system with a resolution of 0.50 minutes per gridcell for the study area. This resolution yields a study area domain that is a matrix of 1080 rows by 540 columns, some 583200 grid-cells with individual sizes of about $0.23 \mathrm{mi}^{2}$ each $\left(\sim 0.58 \mathrm{~km}^{2}\right)$.

\section{Spatial mapping of at-site means}

Spatial mapping of at-site means encompasses a number of separate tasks that address the spatial behaviour of at-site means and seeks to minimise differences between mapped values and sample values computed at precipitation measurement stations. This involved first developing relationships between at-site means computed at precipitation measurement stations and climatic/ physiographic factors. An example of this type of relationship is depicted in Fig. 16 for the eastern slopes of the Cascade Mountains. These relationships were then used to populate the grid-cells in the study area domain with the values predicted from the applicable regression equation based on the climatic and physiographic factors representative of each grid-cell. At-site mean values for gridcells within transition zones 154 and 147 were computed as a weighted average of the at-site mean values in the same manner as if the grid-cell had been located in the adjoining regions. This provided continuity with at-site mean values at regional boundaries and provided a smooth transition between adjoining regions.

Residuals were then computed for each of the station atsite means that quantify the magnitude of difference between mapped values and station values. This allowed analyses of the residuals to identify if there was a coherent spatial pattern to the magnitude and sign of the residuals. When coherent residual patterns were encountered, they were used to adjust the original estimates. Lastly, standard bias and root mean square error measures were computed to quantify the overall

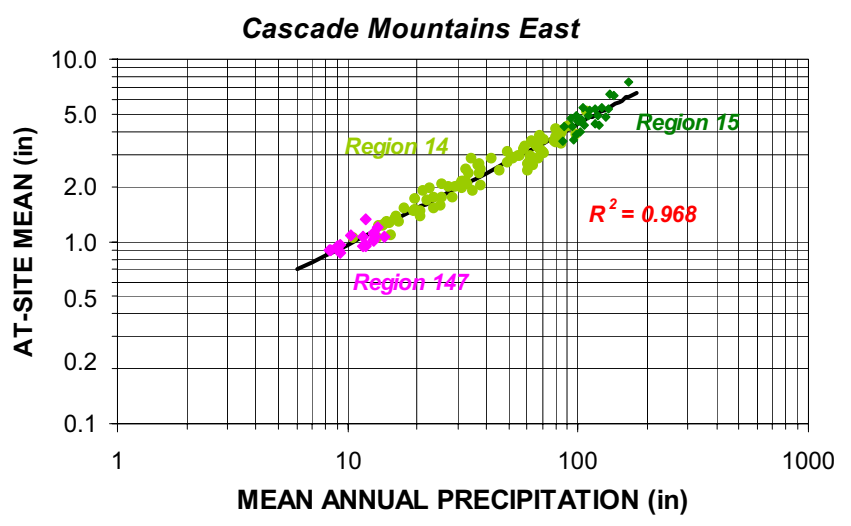

Fig. 16. Example relationship of 24-hour at-site mean with mean annual precipitation for Eastern Cascade Mountains (Regions 14 and 147) 
goodness-of-fit of the mapped values relative to the observations at the gauges. The completed maps of the at- site means for the 24-hour and 2-hour durations are shown in Fig. 17.
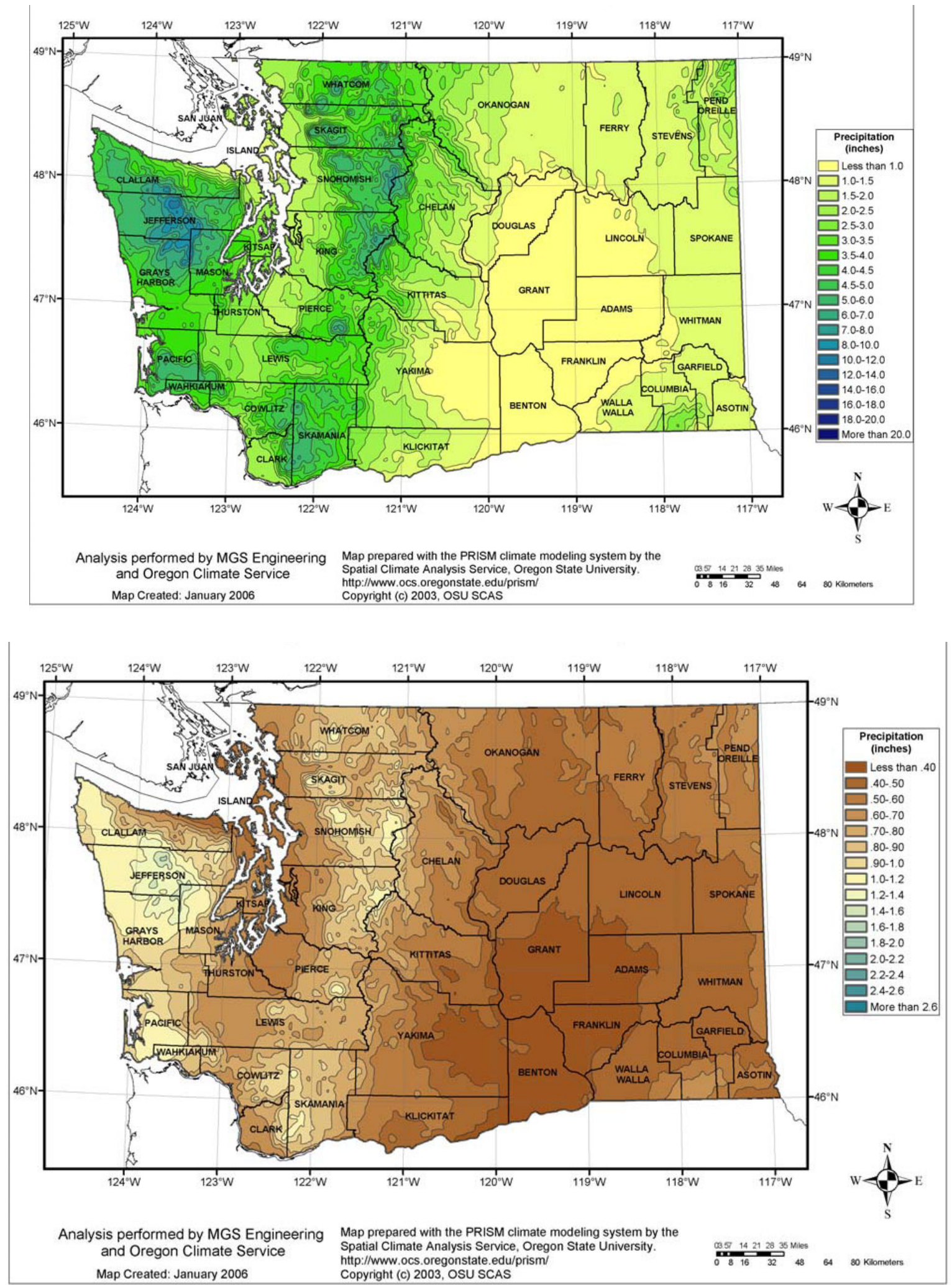

Fig. 17. Map of at-site means (mean annual maxima) at 24-hour (top) and at 2-hour duration (bottom) for Washington study area 
QUANTITATIVE ASSESSMENT OF SUCCESS

\section{ACHIEVED IN SPATIAL MAPPING OF AT-SITE}

\section{MEANS}

A quantitative measure was needed to assess the relative success of the spatial mapping procedures in capturing the spatial behaviour of the at-site means. This is difficult in all studies of this type because the true values of the at-site means are unknown. The logical standard for comparison is the station sample value of the at-site mean. However, sample values of the station at-site mean will differ from the true population values due to sampling variability and other natural and man-related variability associated with precipitation measurement and recording.
This problem was approached by framing the question as; how do the observed station values compare with the final mapped values? Given this question, the bias and root mean square error (RMSE) computations (Helsel and Hirsch, 1992) can be expressed in standardised units using the mapped values as the predicted value. This equates to computing bias and RMSE for the standardised residuals $\left(S R_{2}\right)$ as:

$$
S R_{2}=\left(S-P_{2}\right) / P_{2}
$$

where: $S$ is the observed station value of the at-site mean; and $P_{2}$ is the mapped value of the station at-site-mean.

Table 11 lists the computed standardised residuals. It is

Table 11. Bias and root mean square error of standardised residuals for final mapped values of station at-site means

\begin{tabular}{|c|c|c|}
\hline & \multicolumn{2}{|c|}{ Final mapped values } \\
\hline & Bias & RMSE \\
\hline \multicolumn{3}{|l|}{ (a) 24-hour duration } \\
\hline \multicolumn{3}{|l|}{ WESTERN WASHINGTON } \\
\hline Region 5 - Coastal Lowlands & $-0.6 \%$ & $3.8 \%$ \\
\hline Region 151 - Windward Faces Coastal Mountains & $+1.1 \%$ & $4.0 \%$ \\
\hline Region 142 - Leeward Areas Coastal Mountains & $+2.9 \%$ & $6.9 \%$ \\
\hline Region 32 - Interior Lowlands - West & $-0.6 \%$ & $8.1 \%$ \\
\hline Region 31 - Interior Lowlands - East & $-0.6 \%$ & $4.0 \%$ \\
\hline Region 15 - West Face of Cascade Mountains & $-0.5 \%$ & $5.6 \%$ \\
\hline \multicolumn{3}{|l|}{ EASTERN WASHINGTON } \\
\hline Region 14 - East Face of Cascade Mountains & $-0.0 \%$ & $5.0 \%$ \\
\hline Zone 147 - Transition Zone Cascade Foothills & $+1.2 \%$ & $5.6 \%$ \\
\hline Region 77 - Central Basin & $+0.0 \%$ & $2.9 \%$ \\
\hline Region 7 -Okanogan, Spokane, Palouse & $-0.1 \%$ & $3.4 \%$ \\
\hline Region 13 - Eastern Mountains & $+0.0 \%$ & $4.8 \%$ \\
\hline All Regions & $+0.1 \%$ & $4.9 \%$ \\
\hline \multicolumn{3}{|l|}{ (b)2-hour duration } \\
\hline \multicolumn{3}{|l|}{ Western WASHINGTON } \\
\hline Region 5 - Coastal Lowlands & $+0.2 \%$ & $2.3 \%$ \\
\hline Region 151 - Windward Faces Coastal Mountains & $+1.5 \%$ & $7.8 \%$ \\
\hline Region 142 - Leeward Areas Coastal Mountains & $-1.2 \%$ & $2.5 \%$ \\
\hline Region 32 - Interior Lowlands - West & $-0.4 \%$ & $2.8 \%$ \\
\hline Region 31 - Interior Lowlands - East & $-0.8 \%$ & $3.9 \%$ \\
\hline Region 15 - West Face of Cascade Mountains & $-0.9 \%$ & $3.7 \%$ \\
\hline \multicolumn{3}{|l|}{ EASTERN WASHINGTON } \\
\hline Region 14 - East Face of Cascade Mountains & $-0.5 \%$ & $4.6 \%$ \\
\hline Zone 147 - Transition Zone Cascade Foothills & $-0.1 \%$ & $3.4 \%$ \\
\hline Region 77 - Central Basin & $+0.1 \%$ & $6.7 \%$ \\
\hline Region 7 -Okanogan, Spokane, Palouse & $+0.9 \%$ & $5.1 \%$ \\
\hline Region 13 - Eastern Mountains & $-1.5 \%$ & $5.3 \%$ \\
\hline All Regions & $-0.5 \%$ & $4.5 \%$ \\
\hline
\end{tabular}


seen that the final mapped values of the at-site means are nearly unbiased. If the RMSE values for the stations are representative of the at-site mean maps taken as a whole, then the final maps of at-site means have a standard error of estimate that is near $5 \%$. The RMSE of the final mapped values are generally similar in magnitude to that expected from natural sampling variability and, thus, are as low as can reasonably be expected.

\section{Spatial mapping of regional L- moment statistical parameters}

To compute precipitation estimates for the recurrence intervals selected, the appropriate value of $\mathrm{L}-\mathrm{Cv}$ and $\mathrm{L}-$ skewness must be obtained for each grid-cell. This was accomplished by populating the grid-cells in the study area domain using the functional relationships for L-Cv and Lskewness (Tables 3 and 4) developed in the regional precipitation-frequency analysis. Population of the grid-cells within transition zones 154 and 147 was accomplished as a weighted average of the L-moment ratio values had the gridcell been located in the adjoining climatic regions. The weights were based on the nearness of a given grid-cell to the boundaries of the transition zone. This provided continuity at the boundaries of the regions and a smooth transition between regional boundaries within the transition zones. For Region 154, the need for the transition zone existed only in the drier portions, and then only at the higher recurrence intervals, ( $\mathrm{T}=500$ and beyond).

Colour-shaded maps of L-Cv and L-Skewness values are depicted in Figs. 18a,b and 19a,b for the 24-hour and 2hour durations, respectively. Separate gridded electronic data files may also be accessed at http://www.wsdot.wa.gov/ mapsdata/geodatacatalog/default.htm .

\section{Production of isopluvial maps}

Production of the isopluvial maps was accomplished by incorporating the information described above. For each grid-cell, the applicable values of the at-site mean and Lmoment ratios L-Cv and L-skewness were used to solve the distribution parameters for the four-parameter Kappa distribution (Hosking and Wallis, 1997; Hosking, 1988). The distribution parameters were then used with Eqn. 3 to compute the expected value of the precipitation for the desired recurrence interval. This procedure was repeated for each grid-cell until the domain for the study area was populated. The resultant precipitation field was then contoured to yield isopluvials for selected values of precipitation.

An example of an isopluvial map produced by this process is depicted in Fig. 20, which shows a colour-shaded map of 24-hour 100-year precipitation. Isopluvial maps for the other selected recurrence intervals for the 24-hour and 2-hour durations are contained in Appendix B ( Schaefer et al., 2006).

\section{PRECIPITATION MAGNITUDE-FREQUENCY \\ ESTIMATES FOR MODERATE TO LARGE SIZE WATERSHEDS}

The precipitation magnitude-frequency information contained in the gridded datasets and depicted on the isopluvial maps corresponds to $10-\mathrm{mi}^{2}$ and $1-\mathrm{mi}^{2}$ precipitation for the 24-hour and 2-hour durations, respectively. Estimation of precipitation volumes for larger catchments for a selected recurrence interval requires the application of areal reduction factors, which would be obtained from analyses of historical storms. The topic of areal reduction factors, depth-area-duration analyses, and estimation of precipitation for moderate to large size catchments is beyond the scope of this report. It is mentioned here to alert the reader that precipitation values from the gridded datasets and isopluvial maps need to be scaled by areal reduction factors to obtain estimates of precipitation volumes for moderate to large catchments. Additional information on areal reduction factors can be found in articles by Bell (1976), Meyers and Zehr (1980) and Siriwardena and Weinmann (1996).

\section{UNCERTAINTY BOUNDS FOR 100-YEAR VALUES}

The accuracy of estimation of 100 -year precipitation annual maxima at a given location is dependent upon the success obtained in estimating the at-site mean, and L-moment ratios L-Cv and L-skewness, and the similarity between the chosen probability model (Kappa distribution) and the actual model mother nature is using.

In general, uncertainties associated with the estimation of L-moment ratios L-Cv and L-skewness result in standard errors of estimation of about $5 \%$ at the 100 -year recurrence interval. These relatively low levels of uncertainty are attributable to the very large datasets that were used to estimate the L-moment ratios and identify a suitable probability model. Interaction of these standard errors of estimation with that due to estimation of the at-site mean (Tables 11a,b) yields the standard errors of estimation shown in Table 12. The range in standard errors of estimation for a given duration is due, primarily, to the region-to-region variation of the standard errors for estimation of the at-site mean for the recurrence intervals cited in Table 12.

The values in Table 12 should be considered approximate 


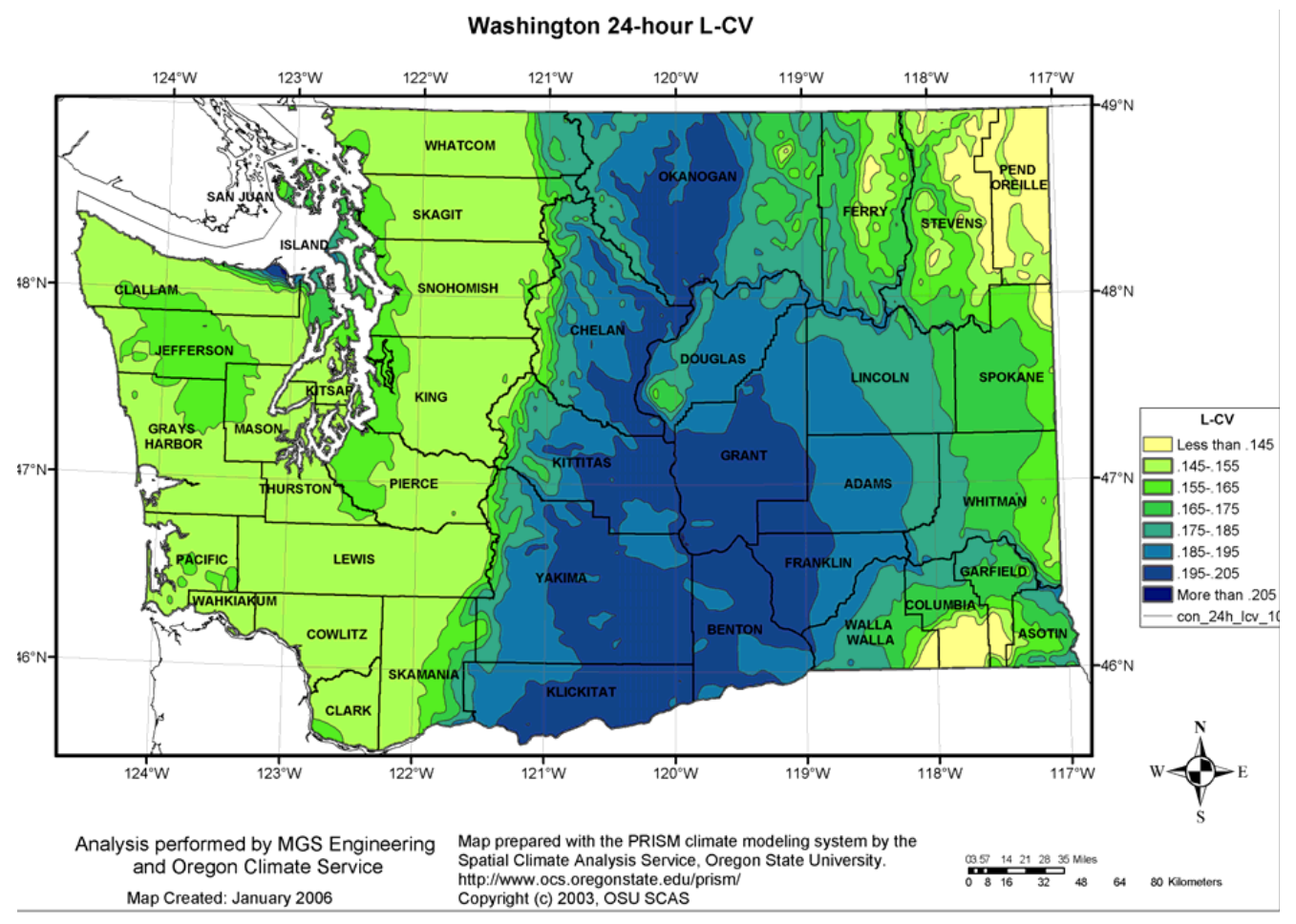

Fig. 18a. Statewide variation of L-Cv annual maximum precipitation at 24-hour duration

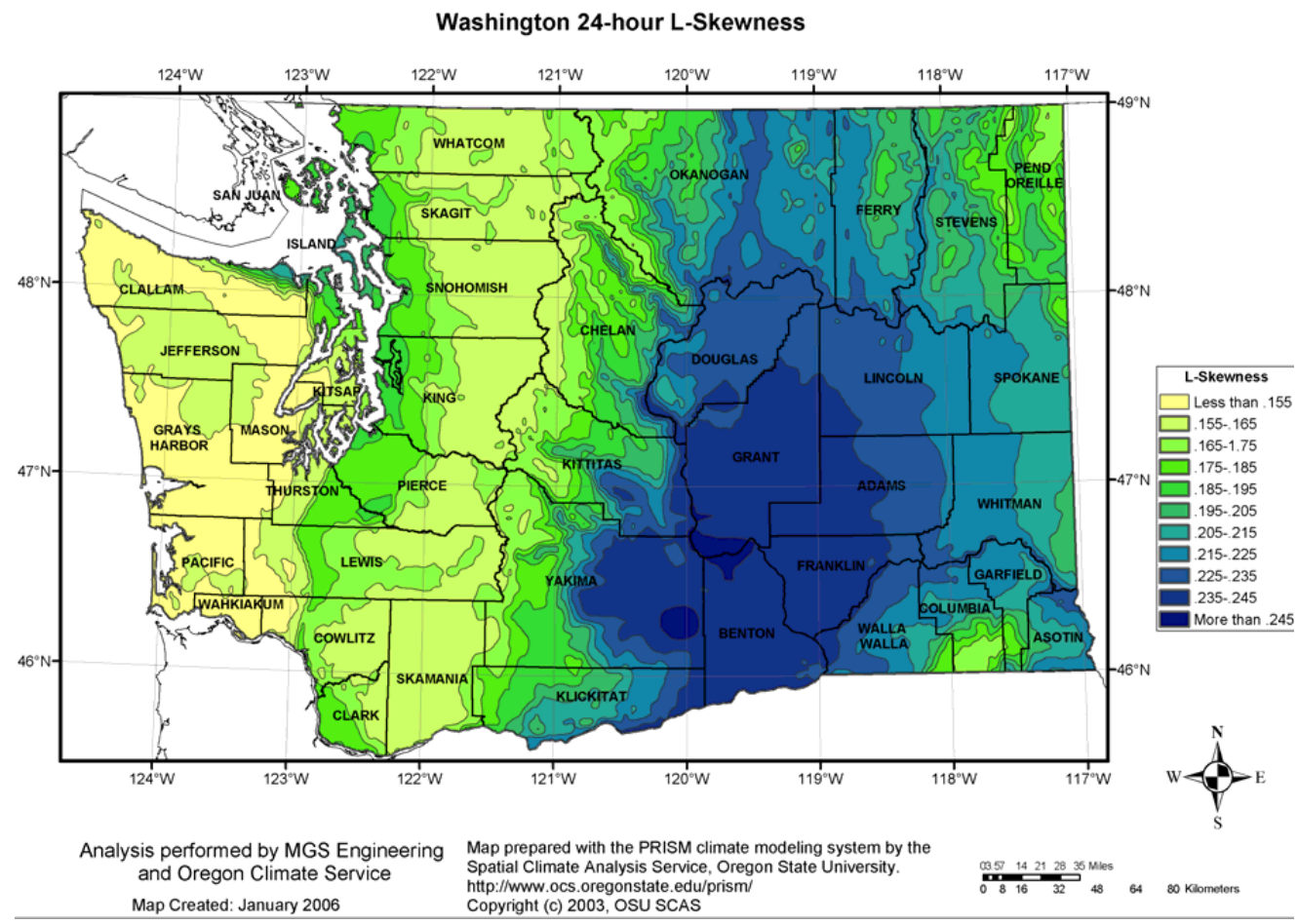

Fig. 18b. Statewide variation of L-skewness of annual maximum precipitation at 24-hour duration 


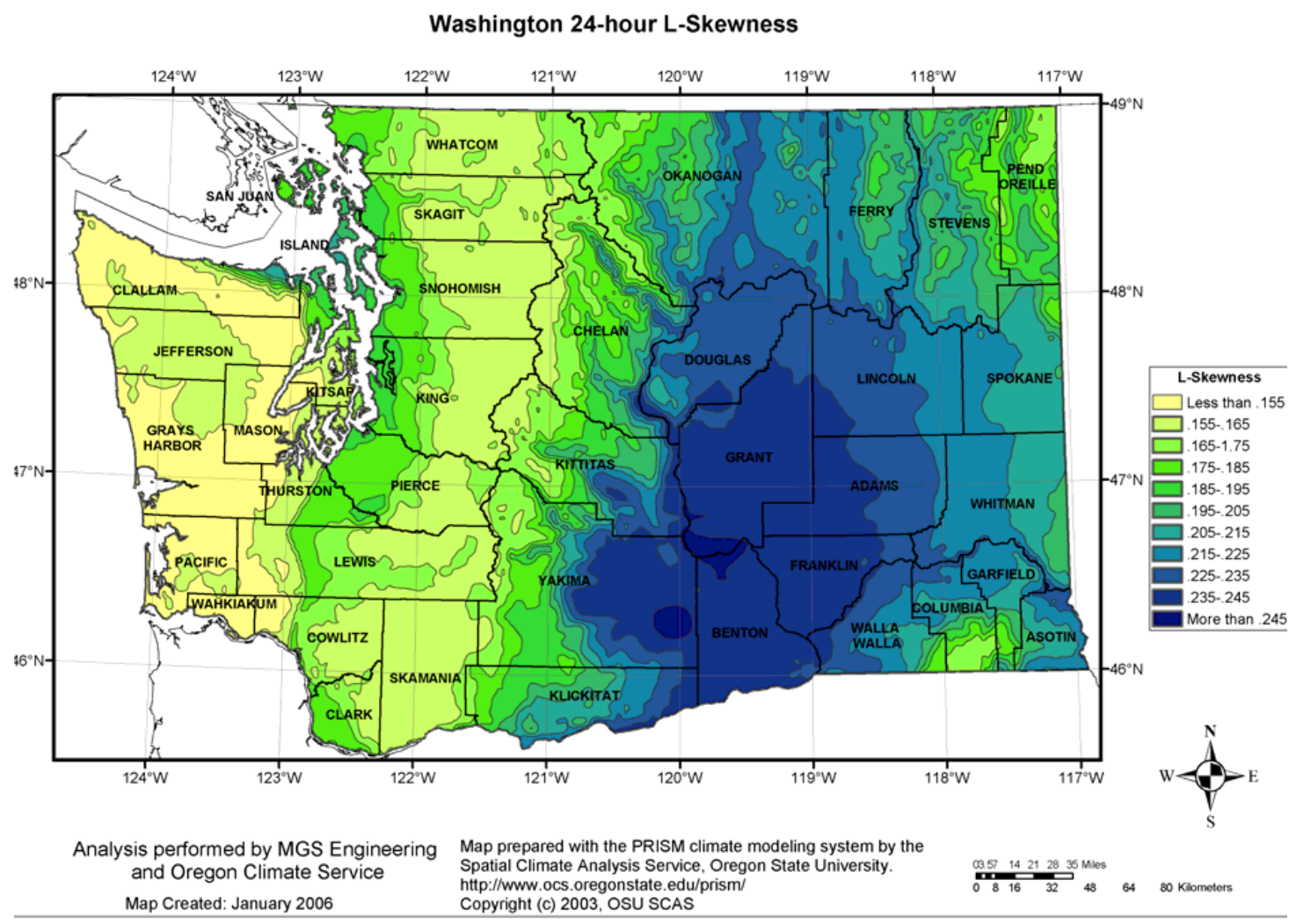

Fig. 19. Statewide variation of $L-C v$ annual maximum precipitation at 2-hour duration

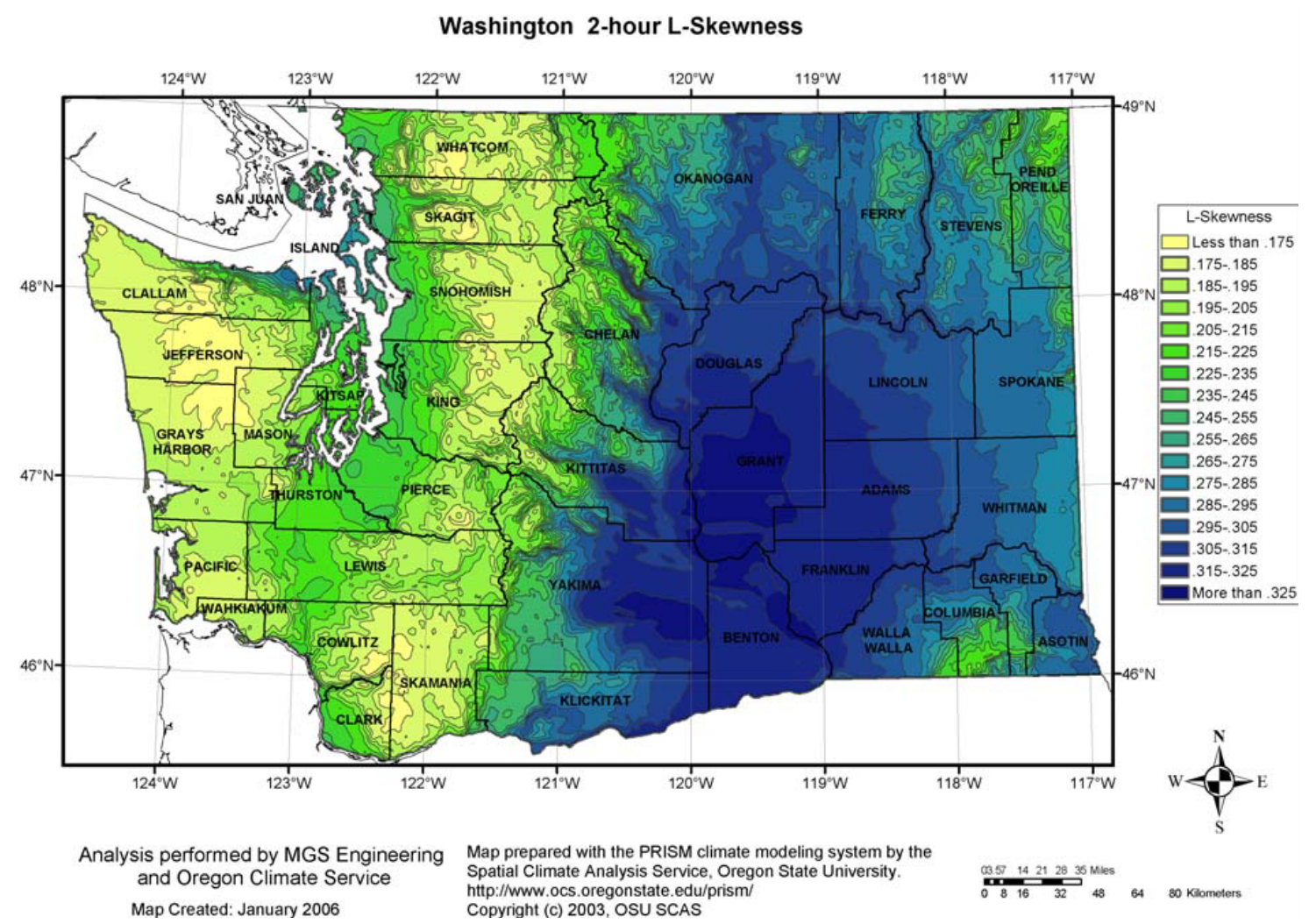

Fig. 19b. Statewide variation of L-skewness annual maximum precipitation at 2-hour duration 


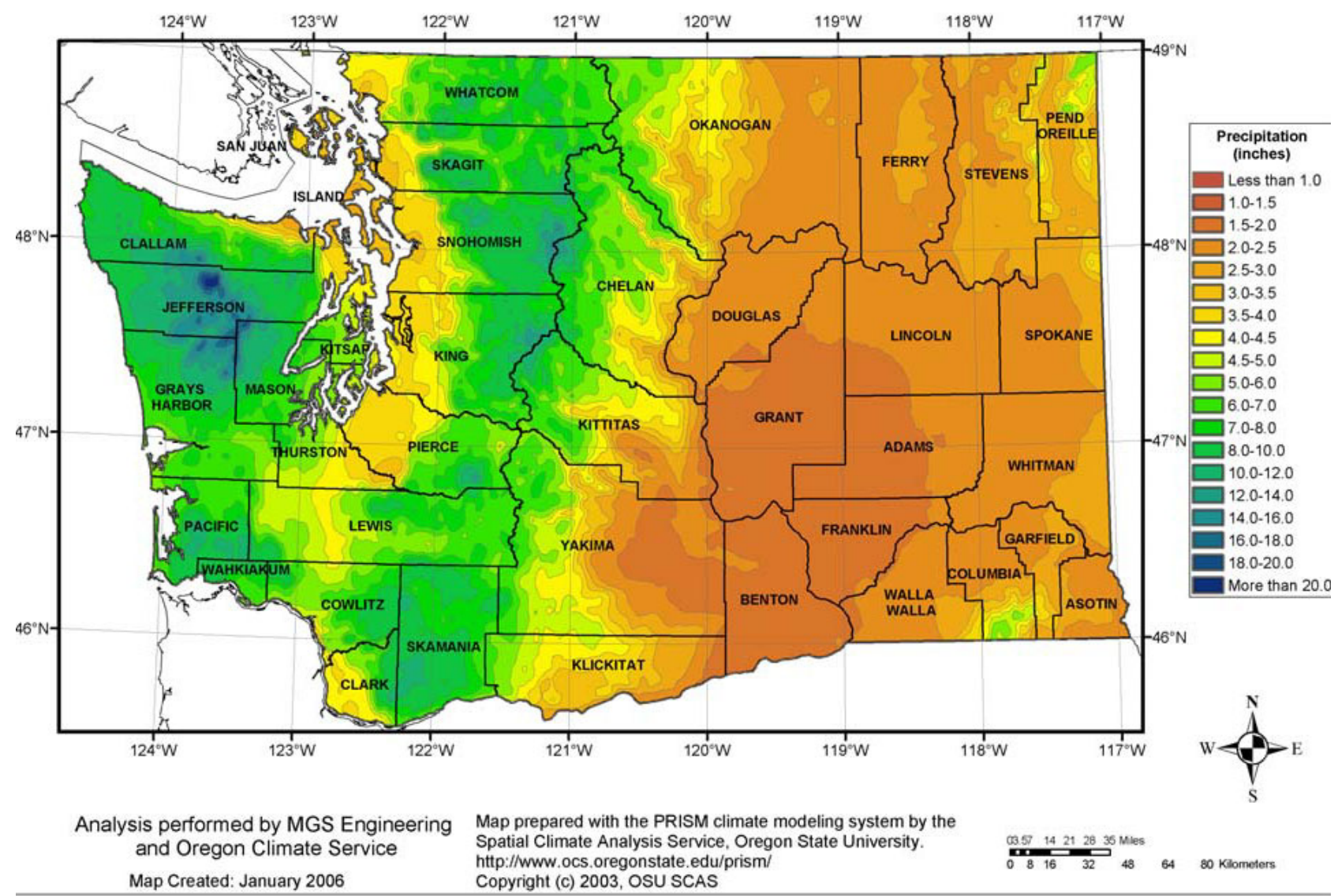

Figure 20. Isopluvial map of 24-hour precipitation for 100-year recurrence interval for Washington State

Table 12. Range of standard errors of estimation for two recurrence intervals, all regions

\begin{tabular}{lcc}
\hline Duration & $\begin{array}{c}\text { Standard error of estimation for precipitation } \\
10-\text { year }\end{array}$ & $\begin{array}{l}100 \text {-year } \\
\text { 2-hour }\end{array}$ \\
24-hour & $4 \%-7 \%$ & $6 \%-10 \%$ \\
& $4 \%-8 \%$ & $7 \%-10 \%$ \\
\hline
\end{tabular}

as detailed studies for computation of uncertainty bounds have not been conducted. Further, these values represent regional averages. Values applicable to a given location may be somewhat smaller or larger than those indicated in Table 12.

\section{Electronic files}

\section{LISTING AT-SITE AND REGIONAL PARAMETERS FOR ALL GAUGED SITES}

Appendix A includes station catalogues for the stations/ gauges used in the study. It also references a compact disc
(CD) containing ASCII text files and Excel spreadsheets listing the precipitation estimates for selected recurrence intervals. Specifically, the files contain the station identification number, station name, type of gauge, climatic region number, latitude, longitude, elevation, mean annual precipitation, sample value of at-site mean, mapped value of at-site mean, regional values of L-Cv, L-skewness, $h$ parameter for the Kappa distribution, and estimated 6-month, 2-year, 10-year, 25-year, 50-year, 100-year and 500-year precipitation.

\section{Seasonality of extreme storms}

The seasonality of extreme storms can be a valuable tool for application of the precipitation-frequency information in rainfall-runoff modelling. Specifically, information on the seasonality of storms is helpful in decision-making for setting catchment conditions antecedent to the storm.

The seasonality of extreme storms was investigated by constructing frequency histograms of the storm dates for rare 24-hour and 2-hour precipitation amounts for each of the four climatic regions (14, 77, 7 and 13). Extreme storms 
were taken to be precipitation amounts with annual exceedence probabilities less than 0.05 (rarer than a 20-year event). Precipitation amounts/gauges with duplicate storm dates (generally dates within about three calendar days) were removed before constructing the frequency histograms for each climatic region. The results of the seasonality analyses are discussed below.

\section{SEASONALITY OF 24-HOUR EXTREME EVENTS}

Well-defined seasonal patterns are apparent for storms that are rare at the 24-hour duration on the east slopes of the Cascade Mountains (Fig. 21a). These storms are the result of synoptic scale cyclonic weather systems and associated fronts. These storms remain organised and penetrate a considerable distance inland from the coast. There is a rapid transition in seasonality of storms at the foothills of the Cascade Mountains into the Central Basin where arid and semi-arid Regions 77 and 7 show both a winter and springsummer seasonality pattern (Fig. 21b). In these arid and semi-arid areas, the spring-summer period has the greater proportion of extreme storms The mountainous areas in northeastern and southeastern Washington show a bi-modal seasonality pattern (Fig. 21c) with both winter and springsummer periods having a similar proportion of extreme storms at the 24-hour duration.

\section{SEASONALITY OF 2-HOUR EXTREME EVENTS}

Storms which are extreme at the 2-hour duration have distinctively different seasonality patterns on the east slopes of the Cascade Mountains versus areas further east. Extreme storms on the east slopes of the Cascades have a bi-modal pattern with extreme storms occurring in both the winter and summer seasons at the 2-hour duration (Fig. 22a). Some of these are localised events having limited areal coverage with precipitation occurring over a relatively short period of time. Other events are embedded in longer duration storm events and are associated with large-scale weather systems having more widespread areal coverage.

Further east, the vast majority of extreme storms occur in the late-spring and summer season (Figs. 22b,c). These storm events are typically associated with localised thunderstorms that may or may not be associated with an organised weather system.

\section{Catalogue of extreme storms}

A catalogue of extreme storms in Appendix C (Schaefer et al., 2006) lists those storm events at the 24-hour and 2-hour durations where the annual exceedence probabilities were less than 0.05 (rarer than a 20-year event). These are the

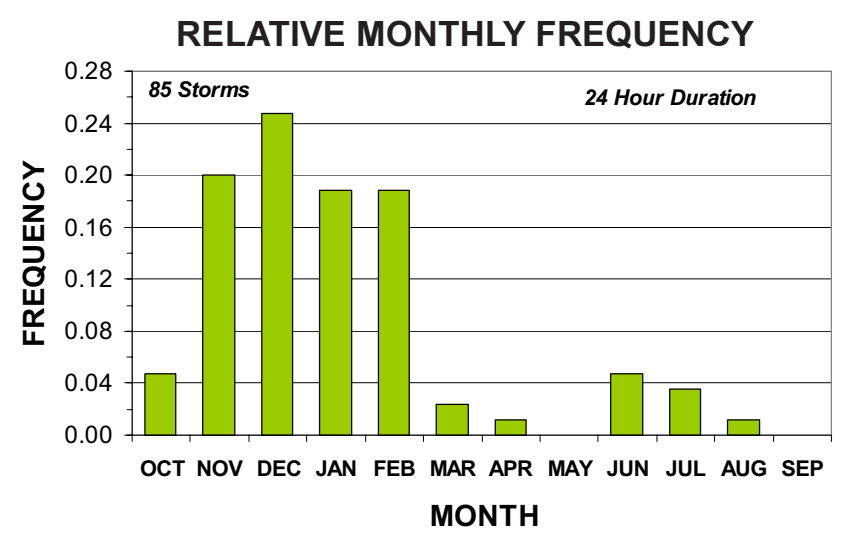

Fig. 21a. Seasonality of extreme storms in Region 14 for the 24-hour duration (east slopes Cascade Mountains)

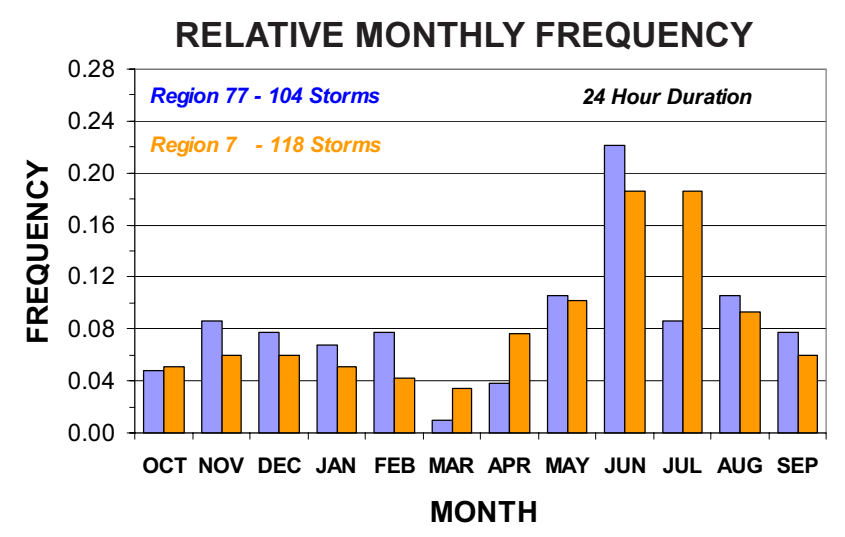

Fig. 21b. Seasonality of extreme storms in Region 77 and Region 7 for the 24-hour duration (Central Basin and Okanogan, Spokane, Palouse)

\section{RELATIVE MONTHLY FREQUENCY}

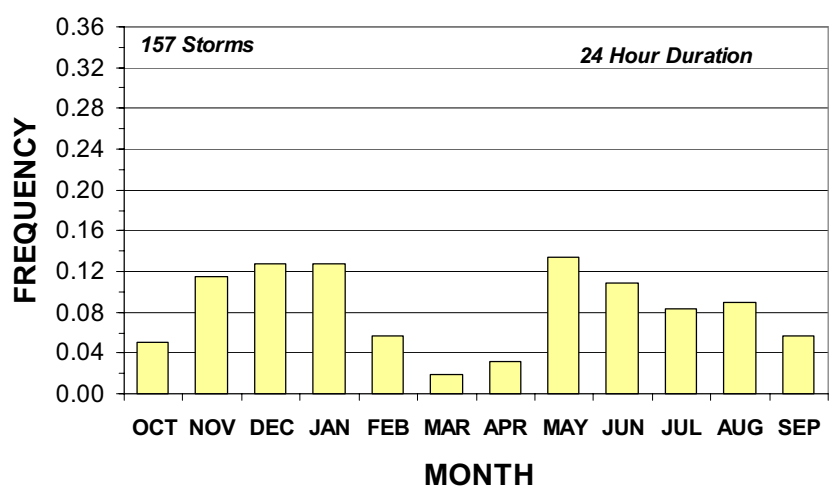

Fig. 21c. Seasonality of extreme storms in Region 13 for the 24-hour Duration (north-eastern and Blue Mountains)

same storm events/storm dates as used in the seasonality analysis. The temporal patterns from these storms would be logical candidates for single event rainfall-runoff modelling of extreme storms. 


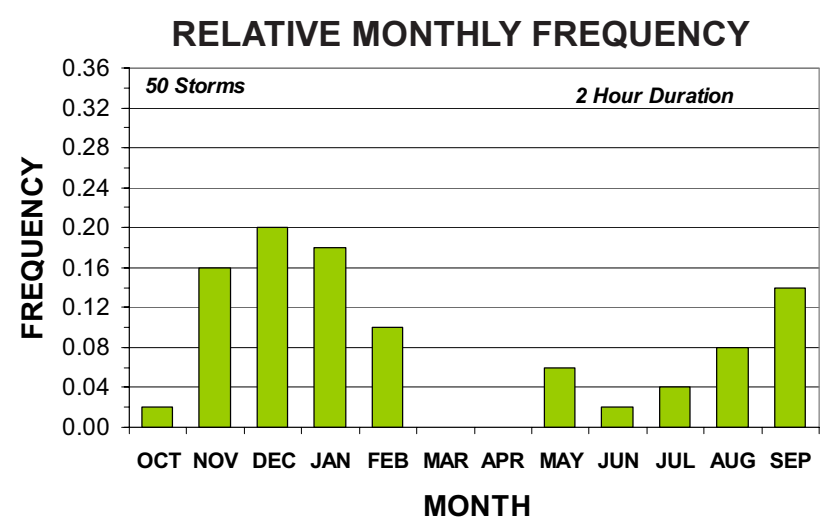

Fig. 22a. Seasonality of extreme storms in Region 14 for the 2-hour duration (East Slopes Cascade Mountains)

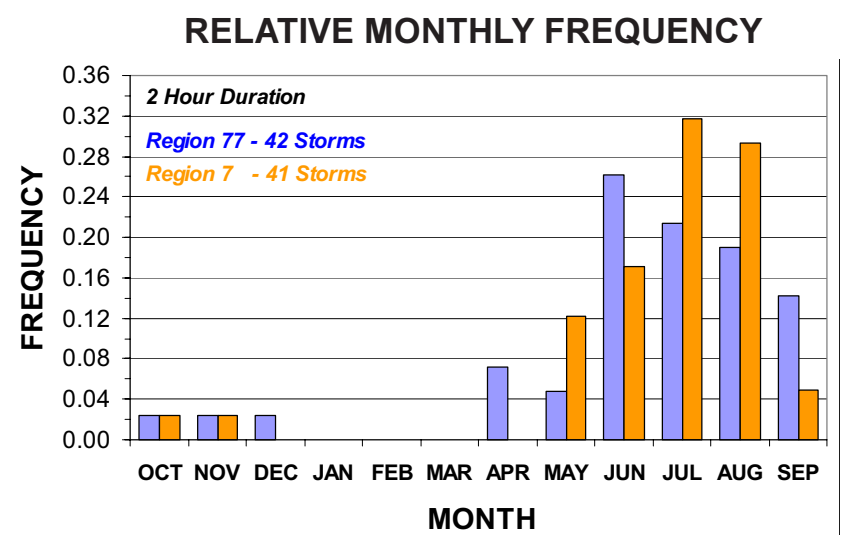

Fig. 22b. Seasonality of extreme storms in Regions 77 and 7 for the 2-hour duration (Central Basin and Okanogan, Spokane, Palouse)

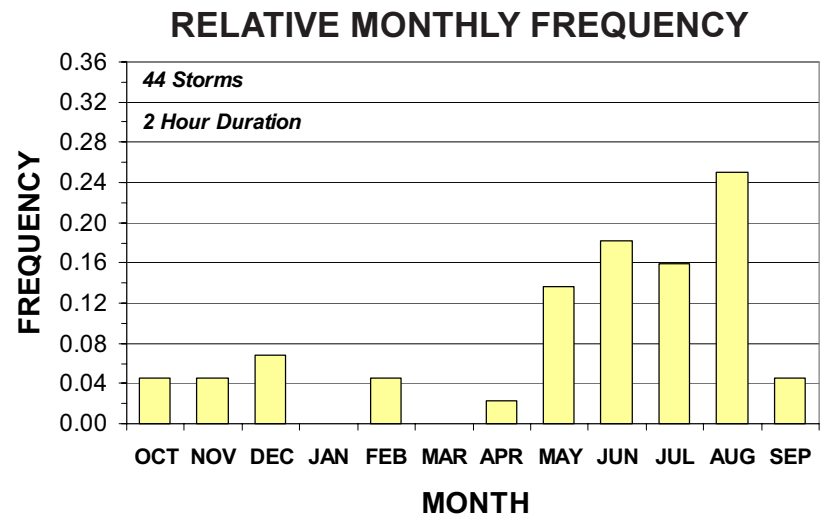

Fig. 22c. Seasonality of extreme storms in Region 13 for the 2-hour duration (north-eastern and Blue Mountains)

\section{References}

Bell, F.C., 1976. The Areal Reduction Factors in RainfallFrequency Estimation. Report 35, Institute of Hydrology, Wallingford UK.

Dalrymple, D., 1960. Flood Frequency Analysis. USGS, Water Supply Paper 1543-A.

Daly, C., Gibson, W.P., Taylor, G.H., Johnson, G.L. and Pasteris, P., 2002. A knowledge-based approach to the statistical mapping of climate. Climate Res., 22, 99-113.

Fiorentino, M.S., Gabrielle, S., Rossi, F. and Versace, P., 1979. Hierarchical approach for regional frequency Analysis. In: Regional Frequency Analysis, V.P. Singh (Ed.), Reidel, Norwell Massachusetts, USA. 35-49.

Helsel, D.R. and Hirsch, R.M., 1992. Statistical Methods in Water Resources. Elsevier Studies in Environmental Science 49, NY, 1992.

Hosking, J.R.M., 1988. The Four Parameter KAPPA Distribution, IBM Research Report RC13412, IBM Research, Yorktown Heights, NY, USA.

Hosking, J.R.M., 1990. L-Moments: Analysis and Estimation of Distributions using linear combinations of order statistics. $J$. Roy. Statist. Soc., Ser B, 52, 105-124.

Hosking, J.R.M. and Wallis, J.R., 1993. Some statistics useful in regional frequency analysis. Water Resour. Res., 29, 271-281.

Hosking, J.R.M. and Wallis, J.R., 1997.Regional Frequency Analysis - An Approach Based on L-Moments. Cambridge University Press, Cambridge, UK.

Langbein, W.B., 1949. Annual floods and the partial duration flood series, Trans. Amer. Geophys. Un., 30, 879-881.

Meyers, V.A. and Zehr, R.M., 1980. A methodology for point-toarea rainfall frequency ratios. NOAA Technical Report NWS 24, NOAA, US Department of Commerce, National Weather Service, Washington DC, USA.

Miller, J.F, Frederick, R.H. and Tracey, R.S., 1973. NOAA ATLAS 2, Precipitation - Frequency Atlas of the Western United States. U.S. Dept. of Commerce, NOAA, National Weather Service, Washington DC, USA.

NWS, National Weather Service, 1966. Probable Maximum Precipitation for the Pacific Northwest. Hydrometeorological Report 43, U.S. Department of Commerce, NOAA, U.S. Weather Bureau, Washington DC, USA.

NWS, National Weather Service, 1994. Probable Maximum Precipitation for the Pacific Northwest. Hydrometeorological Report 57. U.S. Department of Commerce, NOAA, U.S. Weather Bureau, Washington, D.C., USA.

Oregon Climate Service, 2000. Mean Annual Precipitation Map for Southern British Columbia, prepared with PRISM Model for Environment Canada, Corvallis Oregon, USA.

Oregon Climate Service, 2005. Mean Annual Precipitation Maps for United States, prepared with PRISM Model for NRCS, Corvallis Oregon, USA.

Schaefer, M.G., 1989. Characteristics of Extreme Precipitation Events in Washington State. Washington State Dept.of Ecology, Report 89-51.

Schaefer, M.G., 1990. Regional analyses of precipitation annual maxima in Washington State. Water Resour.Res., 26, 119-132.

Schaefer, M.G., 1997. Magnitude-frequency characteristics of precipitation annual maxima in Southern British Columbia, prepared for BCHydro Power Supply and Engineering. MGS Engineering Consultants, Olympia, Washington, USA.

Schaefer, M.G. and Barker, B.L., 1997. Stochastic modeling of extreme floods for A.R. Bowman dam. Report prepared for the USBR by MGS Engineering Consultants, Inc., Olympia Washington, USA. 
Schaefer, M.G. and Barker, B.L., 2000. Precipitation magnitudefrequency characteristics for the American river watershed, prepared for US Army Corps of Engineers, Hydrologic Engineering Center, MGS Engineering Consultants, Olympia, Washington, USA.

Schaefer, M.G., Barker, B.L., Taylor,G.H. and Wallis, J.R., 2002. Regional precipitation-frequency analysis and spatial mapping of precipitation for 24-hour and 2-hour durations in western Washington, prepared for Washington State Department of Transportation, Report WA-RD 544.1, MGS Engineering Consultants, Olympia, Washington, USA

Schaefer, M.G., Barker, B.L., Taylor, G.H. and Wallis, J.R., 2006. Regional Precipitation-frequency analysis and spatial mapping of precipitation for 24-hour and 2-hour durations in eastern Washington, prepared for Washington State Department of Transportation, MGS Engineering Consultants, Olympia, Washington, USA.

Siriwardena, L. and Weinmann, P.E., 1996. Derivation of areal reduction factors for design rainfalls in Victoria for rainfall durations 18-120 hours. Cooperative Research Centre for Catchment Hydrology, Department of Civil Engineering Monash University, Victoria Australia, Report 96/4, October 1996.
Spatial Climate Analysis Service, 2005. Map of mean annual precipitation for the State of Washington for the 1971-2000 period. Oregon State University, Corvallis, Oregon, USA.

Stedinger, J.R., Vogel, R.M. and Foufoula-Georgiou, E., 1992. Frequency analysis of extreme events. In: Handbook of Hydrology, McGraw Hill, USA. Chapter 18.

Wallis, J.R., 1980. Risk and uncertainties in the evaluation of Flood events for the design of hydraulic structures. In: Pienne $e$ Siccita, E. Guggino, G. Rossi, and E. Todini (Eds.), Fondazione Politecnica del Mediterranes, Catania, Italy. 3-36.

Wallis, J.R., 1982. Hydrologic problems_connected with oil-shale development. In: Environmental Systems and Management, S. Rinaldi, (Ed.), North Holland, Amsterdam, The Netherlands. $85-102$.

Wallis, J.R., 1997. Personal Communication.

Wallis, J.R., Lettenmeier, D.P. and Wood, E.F., 1991. A daily hydro-climatologic data set for the Continental US. Water Resour.Res., 27, 1657-1663. Data available free on two CDROMS from the Oak Ridge National Laboratory, Oak Ridge, Tennessee.

Weiss, L.L., 1964. Ratio of true to fixed interval maximum rainfall, J. Hydraul. ASCE, 90(HY1), 77-82. 